Nova Southeastern University

NSUWorks

College of Psychology Theses and Dissertations

College of Psychology

$1-1-2014$

\title{
Attachment Style and Psychological Sense of Community in the Context of 12-Step Recovery
}

\author{
Amy Elizabeth Ellis \\ Nova Southeastern University, amyellisphd@gmail.com
}

This document is a product of extensive research conducted at the Nova Southeastern University College of Psychology. For more information on research and degree programs at the NSU College of Psychology, please click here.

Follow this and additional works at: https://nsuworks.nova.edu/cps_stuetd

Part of the Psychology Commons

\section{Share Feedback About This Item}

\section{NSUWorks Citation}

Ellis, A. E. (2014). Attachment Style and Psychological Sense of Community in the Context of 12-Step Recovery. .

Available at: https://nsuworks.nova.edu/cps_stuetd/98

This Dissertation is brought to you by the College of Psychology at NSUWorks. It has been accepted for inclusion in College of Psychology Theses and Dissertations by an authorized administrator of NSUWorks. For more information, please contact nsuworks@nova.edu. 
Attachment Style and Psychological Sense of Community

in the Context of 12-Step Recovery

by

Amy E. Ellis

\begin{abstract}
A Dissertation Presented to the School of Psychology
of Nova Southeastern University

in Partial Fulfillment of the Requirements

for the Degree of Doctor of Philosophy
\end{abstract}

NOVA SOUTHEASTERN UNIVERSITY

2014 
This dissertation was submitted by Amy E. Ellis under the direction of the Chairperson of the dissertation committed listed below. It was submitted to the School of Psychology and approved in partial fulfillment of the requirements for the degree of Doctor of Philosophy in Clinical Psychology at Nova Southeastern University.

Approved:

Date of Defense

Christian DeLucia, Ph.D., Chairperson

Jan Faust, Ph.D.

Steven Gold, Ph.D.

Date of Final Approval

Christian DeLucia, Ph.D., Chairperson 


\section{Acknowledgements}

To Christian, thank you for unfailingly acting as my secure base throughout graduate school and non-judgmentally accepting my idealistic fantasy of opening up a bakery shop. A true mentor and teacher, you have encouraged me to discover my talents and passions. Your encouragement allowed me to jump and reach for the stars at a time when I was feeling that I could not even stand.

To Steve, thank you for a deep and meaningful internal working model that has carried across all aspects of my life. Your compassion and dedication to your work (and life) has had a profound impact on the lens through which I view the world.

To Jan, thank you for your constant willingness to provide support and direction. From the very beginning, you encouraged the development of my autonomy and independence as a clinician, individual, and professional.

To my husband, Jeff, thank you for always knowing how to comfort me through this educational quest. You truly deserve a doctorate in psychology after all the support you have provided, the editing and reviews of this work, and the innumerable theoretical conversations we have shared on attachment.

To my Mom, thank you for your untiring support of my chosen career path as a psychologist. It is no easy task being the mother of a psychologist; thank you for enduring it all and know that despite what Freud said, it really isn't all your fault.

To Millie and Bouche, thank you for all the sacrifices you made and for the timeless love you have given me.

To Sarah Briggs, thank you for being the greatest and most important social support during my graduate school years. You were by my side as I navigated this roller coaster of life and our friendship has only grown stronger.

To my Exploring the Journey Family, thank you for teaching me the true value of a sense of community, belonging, and connection. 


\section{Table of Contents}

List of Tables................................................................ vi

List of Figures.................................................... vii

Abstract.................................................................. 1

Introduction............................................................ 2

Theories of Substance Abuse Etiology................................ 3

Broad Theory of Attachment....................................... 6

Conceptual Roots of Attachment Theory and the Internal Working Model... 7

The Identification and Classification of Attachment Styles................ 10

The Significance of Relationships with Others.......................... 14

Insecure Attachment as a Pathway to Substance Abuse Problems............ 15

The Empirical Literature............................................ 17

Intersection of 12-step Recovery with Attachment Theory as a Pathway Out

of Substance Abuse Problems.................................... 21

Social Support as a Mechanism of Change in 12-step Recovery............. 21

Program Aspect of 12-step Recovery................................... 24

Fellowship Aspect of 12-step Recovery.............................. 25

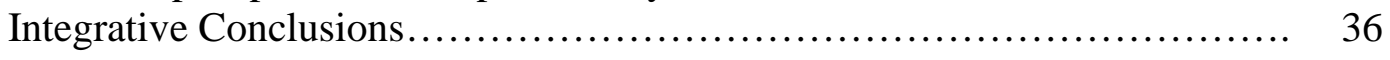

Project Goals and Contribution to the Field............................ 40

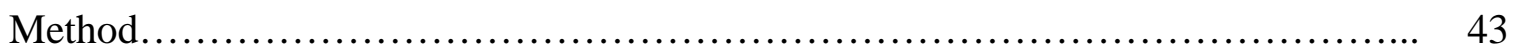

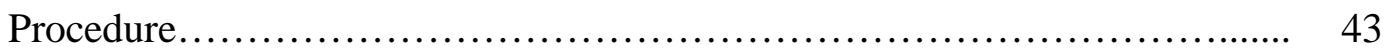

Participants..................................................... 43

Measures.............................................................. 44

Results................................................................ 51

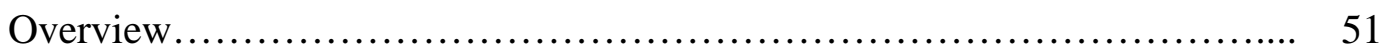

Association Between Nominal and Ordinal Attachment Style Ratings........ 52

Individual Effects of Predictors on Attachment Groups.................... 54

Relative Contribution of Predictors to a Base Model on Attachment Groups... 63

Odds Ratios for Categorization in the Secure Attachment Style............. 66

Attachment Style as a Predictor of Psychological Well-Being.............. 69

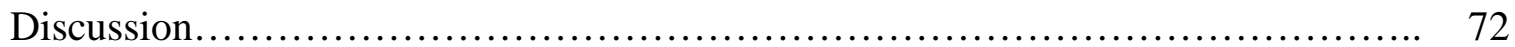

Multidimensional Nature of Attachment................................ 72

Predictors of Attachment............................................ 72

Differentiating the Four Styles of Attachment.......................... 77

Attachment and Recovery-Related Variables as Predictors of Psychological

Well-Being...................................................... 79

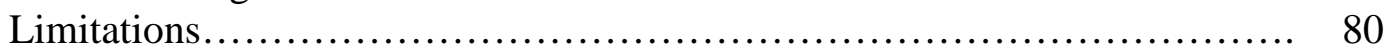

Conclusions, Strengths, and Future Directions........................ 81 
References........................................................... 84

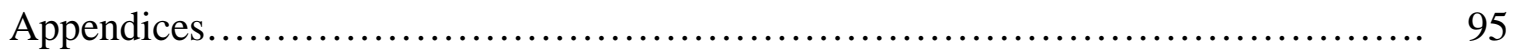

Appendix A - Social Support (SOSU).............................. 95 


\section{List of Tables}

Table 1. Means and standard deviations of recovery-related predictors.

Table 2. Odds ratios for categorization in the secure attachment style. 


\section{List of Figures}

Figure 1. Bartholomew \& Horowitz' (1991) model of adult attachment.

Figure 2. Proposed pathway by which attachment-related experiences lead to SUDs (adapted from Flores, 2004).

Figure 3. Flow of variables throughout analyses predicting attachment. 


\begin{abstract}
Approximately $10 \%$ of adults living in the United States meet criteria for a Substance Use Disorder. Although 12-step groups are considered evidence-based practices for substance use problems, an understanding of the underlying mechanisms by which they facilitate recovery practices remains in its infancy. The purpose of the current study was to explore whether attachment could be considered a possible mediator of the effects of recovery practices on positive psychosocial outcomes. Participants $(N=112)$ were self-identified NA members from 26 U.S. states who completed an online survey assessing attachment style, psychosocial sense of community, psychological well-being, and various other recovery and psychosocial constructs. Results indicated a number of recovery-related practices emerged as significant predictors of secure attachment, over and above covariates. For example, higher levels of home group comfort were associated with increased probability of secure attachment classification (by self-report). In general, psychological sense of community did not significantly predict secure attachment, over and above covariates. Although attachment predicted psychological well-being in univariate models, it generally failed to predict psychological well-being in models that included covariates and recovery-related predictors. Theoretically, these data suggest that functional social support variables are primary recovery-related predictors implicated in NA-involvement, above and beyond other structural social support variables. This further suggests that attachment-related dimensions of 12-step interventions may be integral to recovery outcomes.

Keywords: Narcotics Anonymous, 12-step recovery, attachment theory, social support, psychological sense of community, psychological well-being
\end{abstract}


Attachment Style and Psychological Sense of Community in the Context of 12-Step

\section{Recovery}

Problematic substance use is a problem of great public health significance with recent lifetime prevalence estimates at 10\% (Compton, Thomas, Stinson, \& Grant, 2007).

Often, substance use disorders present as chronic disorders with comorbid depression and anxiety. In a large community-based sample of over 43,000 individuals across the United States, participants were assessed on their alcohol, drug, and mood disorder symptoms. Results indicated that among individuals who endorsed a substance use disorder diagnosis approximately 20\% experienced an independent mood disorder and $18 \%$ experienced an independent anxiety disorder within a one-year period. Furthermore, participants with substance use disorders were more likely to be diagnosed with a specific phobia or major depressive disorder (Grant et al., 2004). Collectively, these data indicate that individuals with substance use disorders often experience a multitude of symptoms that greatly impair their overall psychological well-being.

Given the prevalence and potential impact of substance use disorders, mutual-help groups (such as Alcoholics Anonymous and Narcotics Anonymous) have proliferated in the past several decades. Recent data suggest that approximately five million people attend addiction mutual-help groups annually (Substance Abuse and Mental Health Services Administration, 2008). Specifically, $6 \%$ of adults ages 25-74 have reported attending substance-related 12-step groups (Kessler, Mickelson, \& Zhao, 1997). In addition to being widely accessible and utilized, 12-step groups are currently considered evidence-based substance use practices - given an expanding literature documenting the 
positive effects of these organizations on substance-related and other outcomes of public health significance (Humphreys et al., 2004).

\section{Theories of Substance Abuse Etiology}

Substance abuse is viewed as a developmental disorder, as it changes over time from adolescence (the average time of onset) through adulthood (Chassin, Ritter, Trim, \& King, 2003). Research into the etiology of substance abuse has resulted in several proposed theories (see Hawkins, Catalano, \& Miller, 1992; Petraitis, Flay, \& Miller, 1995; Sher, 1991; Chassin et al., 2003, for reviews). The various theories have resulted in meaningful frameworks that may help practitioners and researchers identify and understand various risk factors ranging from intrapersonal to macro-environmental (Chassin et al., 2003). These theories have also influenced the field's understanding of effective treatment strategies and outcomes.

A commonality across theories is they suggest SUDs are part of a larger and more complicated system. Undoubtedly, the development of SUDs occurs within a contextual framework with various mediated and moderated pathways (see Sher 1991, p. 138 for a heuristic schematic). Sher (1991) proposes that there are three overarching models of vulnerability to substance use, one of which specifically examines psychological concepts such as the experience of negative mood, sensation seeking and impulsivity, and a lack of appropriate coping mechanisms. These common threads among the several current etiological theories allows for an understanding of how they converge with attachment theory as a possible theory for SUDs development.

It is suggested that SUDs develop when individuals are sensitive to the reinforcing effects or insensitive to the punishing effects of substances. One such theory 
is the self-medication or tension-reduction hypothesis, which posits that SUDs relieve stressful feelings by reducing negative emotions (Sher, Grekin, \& Williams, 2005). The research on the validity of this theory has remained inconclusive, however. There are several reasons for the contradictory findings. For one, repeated substance use may lead to tolerance effects whereby the body reestablishes a baseline level. This then reduces the initial feelings of euphoria that the substance may elicit (Sher, Grekin, \& Williams, 2005). The resulting effect on mood is negative; thereby complicating the theory that substance abuse attenuates the effect of negative emotions.

Speaking to this, an alternative sub-hypothesis has been proposed - individuals may resort to drinking or engaging in substance use to counteract the negative emotion when they lack alternative coping mechanisms. For example, one study assigned participants to take a test that was either solvable or unsolvable. Afterwards, participants were offered alcohol and instructed that they would be given a second test of equal or greater difficulty. Alcohol consumption increased for those who took the unsolvable test, as compared to those in the solvable test condition. Drinking behavior decreased, however, when the participants were offered a study guide (Tucker, Vuchinich, \& Sobell, 1981). One interpretation of these data is that depending on the situation, alternative adaptive coping resources will be utilized—when available_-over substance use. For example, social influences and familial conflict have been identified as more cogent risk factors in predicting substance abuse (Rohde, Stice, Gau, \& Martin, 2012). Therefore, it seems that the putative self-medication pathway is best understood utilizing a contextual understanding of the available resources, coping mechanisms, and situational stressors that face an individual. 
Another proposed theory is that substance use is just one facet of more global problem behaviors. Krueger and colleagues (2002) found that antisocial behavior, conduct disorder, alcohol dependence, drug dependence, and constraint all loaded onto a common factor of externalizing behavior. Within this model, genetics also account for a portion of the association between drug/alcohol dependence and conduct disorder (Slutske et al., 1998). In sum, the authors suggest that substance dependence can be understood as being one form of externalizing behavior. Chassin, Pitts, DeLucia, and Todd (1999) investigated the externalizing pathway in a longitudinal study of children of alcoholics and demographically matched children of non-alcoholic parents. The authors found that adolescent externalizing symptoms partially mediated the effects of parental alcoholism on young adult substance use and dependence. This study suggests that externalizing problems are a risk factor for SUDs. Taken together, both studies highlight possible associations between substance use and externalizing problems.

Attachment theories have also been used to explicate the etiology of SUDs. Although the above models and attachment theory models for SUD etiology have evolved in a parallel manner, the attachment theory models are more theoretical in nature and lack the level of empirical investigation of some other proposed etiological pathways. There are perhaps some points of overlap between attachment models and the models described above. For example, the deviance-proneness model has been used to explain substance use in temperamentally "difficult" individuals with self-regulation deficits (Chassin et al., 2003). At the root of this model is the hypothesis that their proneness to conduct problems is due to poor parenting. Low levels of discipline, in combination with low social support, have shown to increase substance use in adolescents (Stice \& Barrera, 
1995). Without the proper affect regulation skills being transmitted to children, the result is poor ego control (Chassin et al., 2003), and in relation to this, insecure attachment.

Sher's (1991) second model of substance use, referencing several psychological attributes, is perhaps the most pertinent to a discussion of attachment-related constructs in the substance use population. In infancy, children establish emotion regulation, patterns of interaction and trust with others (primarily caregivers), and secure attachments. Gold's contextual model of psychotherapy posits, "growing up in an ineffective inter-personal context interferes with basic aspects of functioning developing adequately in the first place" (Gold, 2012). The model is useful in explaining the nature of the individual's family environment as playing an integral role in the development of the child. Without appropriately teaching skills in daily functioning, the child becomes deficient in a variety of milieus. Accomplishing these tasks allows for children to develop healthy psychological, emotional, and mental development. In turn, when these tasks are not successfully accomplished, maladaptive functioning occurs which raises the propensity for internalizing and externalizing disorders (Cicchetti, 1993). As described above, the empirical evidence linking externalizing problems with SUDs is more conclusive although there is some support for the internalizing pathway too (Chassin et al., 1999).

\section{Broad Theory of Attachment}

Attachment theory, as it applies to the substance abuse population, must first be understood in the context of its historical roots. Though the literature is extensive, only a select few gestalt concepts will be presented, as they have direct implications for SUD development, and furthermore, with 12-step recovery practices. Biological in nature, attachment is defined as a bond between caregiver and child that ensures survival. In 
most mammalian relationships, the caregiver is the biological mother; however, it should be noted that the attachment relationship can involve either gender, biological or unrelated. In infancy, close proximity to the caregiver ensures physical survival because infants are unable to feed or defend themselves. The primary caregiver provides nourishment and protection against external threats. The pattern that emerges is that when infants become frightened or distressed they are gratified, soothed, and satiated by the caregiver. Though the basic needs are primarily related to physical concepts, there are emotional and psychological components that are indirectly addressed as well. Attachment is defined as "an inherent mechanism...that drives them [infants] to seek proximity and comfort from attachment figures when frightened or in need of protection and security" (Slade, 2004, p.271). Attachment then, is a process of internalizing the affect regulatory processes of emotional security, comfort, and warmth that were once provided by the caregiver.

\section{Conceptual Roots of Attachment Theory and the Internal Working Model}

At the same time as biological and ethnological studies were being conducted, John Bowlby began constructing attachment theory, an offspring of object-relations theory. As opposed to the term "object" (which may refer to a wide array of concepts), Bowlby (1969) preferred the term "attachment figure" as it incorporates the "bi-personal" nature of the relationship. In other words, the infant does not simply relate to the caregiver independently of all other factors. The relationship works in a bi-directional capacity, as the caregiver also becomes attached to the child. And, there is a global relationship between the two that exists. Theorists have argued that a primary motivation unifying mammalian behavior is to seek out relationships (Fairbairn, 1958). 
Attachment theory focuses on the actual external reality; real experiences within interpersonal relationships are of focus, not necessarily what is innately occurring within the individual. These external forces are then internalized within the infant. In particular, the attachment relationship becomes internalized via the Internal Working Model (IWM). The term stems from the fact that it is an internal mental representation of the other person that acts as a model or prototype of the person in the relationship. The IWM is used as a guide for future relationships for which the person can rely on for information on how to act or respond. The most important facet of the IWM is that it is always “working” and ever changing, easily modified with new experiences and new relationships (Watson, 2002).

Both members of the dyad shape the IWM - not the infant alone (Flores, 2001). Thus, the emotional availability of the caregiver plays a critical role in the development of the working model. Parental reflective functioning refers to the capacity of the mother to understand the infant, his mental states, and his emotions and simultaneously communicate this back to the infant so that he has a sense of his own mind (Fonagy, Target, Gergely, \& Jurist, 2001). Research has shown that parental reflective functioning mediates the transmission of attachment between caregiver and infant (Slade, Grienenberger, Bernbach, Levy, \& Locker, 2005). The reflective capacity of the caregiver is internalized leading to the development of an IWM that allows the infant to appropriately manipulate his or her environment. It acts as an internal script for how the individual can anticipate and prepare for various interpersonal situations and events. As would be expected, without a fully developed and intact IWM, pathological functioning is more likely to result (Bretherton, 1992). 
IWMs create different patterns of interaction that the individual engages in (Lechliter, 2008). In a successful and well-developed IWM a secure base is formed. In effectively responding to the infant and his mental states, exploration of the environment is encouraged. When the child becomes distressed, having a secure base allows for him to return to the caregiver and "fill-up" on the safe haven of the emotionally fulfilling relationship (Marvin, Cooper, Hoffman, \& Powell, 2002). This is seen in the interaction that occurs between mothers and infants in an unfamiliar playroom. Securely attached infants will be comfortable with gravitating away from the mother to explore a new toy or the room. However, it is almost inevitable that the infant will become frightened by either an external cue or perhaps by his own fear of leaving the comfort of his mother. This fear can be quenched through a variety of means such as simply glancing at his mother for reassurance that she is still being attentive or perhaps going to his mother to sit on her lap. The "refueling" allows the infant to again embark on further exploration. This pattern results in the "Circle of Security" where the infant is able to internalize the attachment relationship in a healthy and fulfilling manner (Marvin et al., 2002). Through exploration of one's environment, other skills are honed and developed. For example, cognitive, social and psychological skills are supported (Lechliter, 2008).

Attachment serves multiple adaptive functions. For one, it ensures that the most basic of needs are provided. For example, food, shelter, and protection are given to the infant. But this is not entirely one-sided. The parent derives something as well; that is, the need to feel needed. The attachment relationship also gives the infant a sense of security and thereby reduces fears. Consequently, with reduced fears, exploration of one's environment is enabled. This allows the child to continue to experience his environment 
and foster neuroplasticity, the human brain's ability to develop new neuronal connections as a direct result of experience. Another advantage is that the relationship provides a model for the potential to develop other relationships (Watson, 2002). Attachment relationships offer lifelong contributions to the healthy development of the infant into and throughout adulthood.

\section{The Identification and Classification of Attachment Styles}

Attachment styles in childhood. Ainsworth and colleagues' (1978) pivotal research using the "Strange Situation" resulted in the identification of different attachment styles. Ainsworth was able to classify three styles in which the child and the parent demonstrate certain behavioral patterns. The current state of the research indicates that there is a four-style conceptualization (Main \& Solomon, 1986).

Secure attachment style. In the "Strange Situation," a securely attached child displays distress when their parent leaves and will seek reassurance from them upon their return. As in the "Circle of Security" (Marvin et al., 2002), the child is reassured easily and is comfortable with exploration of their environment in the presence of the parent. The parent illustrates an awareness of their child's emotions by being consistent in responding and attending to their cues. In adulthood, a securely attached individual is able to form emotionally close relationships with others resulting in a mutual dependence and intimacy balanced with autonomy and individuation.

Anxious-avoidant attachment style. The child classified as anxious-avoidant (also referred to as dismissing-avoidant) does not display discomfort or distress in the absence of their parent. Upon their parent's return, the infant does not solicit contact with the parent. Though the child's attention is directed toward the surroundings rather than 
the caregiver, he does not express much positive enthusiasm towards environment. Similar avoidance behaviors are seen in the parent through a lack of touching and response to emotional cues, such as the child's request for comfort. Rather than focusing on the interpersonal relationship, the parent tends to emphasize goal-directed achievements. In this regard, more weight is placed on the external environment rather than the internal world of the infant. Adults with an anxious-avoidant attachment style act independently of others, demonstrate a tendency to mask their true feelings, and show little regard for close affiliative relationships.

Anxious-ambivalent attachment style. The anxious-ambivalent attachment style (also referred to as preoccupied) is characterized by the infant's distress when the parent leaves, with a mixture of anger and anxiety upon their return. The child's ambivalence is further displayed by an overdependence on the parent resulting in an inability to navigate the environment. The parent, in return, is also ambivalent. He or she is inconsistent in response to the infant's emotions, portraying extremes of either unavailability or intrusiveness. There is a strong disconnect between the child's actions and emotions and the parental response. As individuals mature with this type of attachment style, the ambivalence is continued into interpersonal relationships. Adults with an ambivalent style tend to illustrate these mixed feelings by both wanting and rejecting feelings of emotional closeness.

Disorganized attachment style. The final category of the disorganized style is best described as a combination between the avoidant and ambivalent styles. Behaviors on the part of the infant are extreme with little capacity to have or solicit the fulfillment of his emotional needs. The parent in this dyad typically is unable to be emotionally 
responsive, resulting in emotional neglect and abuse. They may also be experiencing their own depression, which impacts their ability to parent healthily. Lastly, these parents are vulnerable to engaging in some form of child abuse. As such, this theory posits that children who grow up with this type of attachment mature into adults who may have long histories of trauma that affects daily living and functioning, especially to the point of lacking affect regulatory skills since they were never internalized.

It is important to note that attachment is formed not based solely on providing basic survival needs, but rather, emotional and social needs. Therefore, the person to whom the child attaches may be different from the person who provides basic care (e.g., changing diapers, feeding) (Schaffer \& Emerson, 1964). Attachment is typically stable throughout one's lifetime. Infants who had participated in the "Strange Situation" were re-interviewed as young adults as part of a longitudinal study. Results indicated that $72 \%$ of individuals had maintained the same secure or insecure attachment style with their own child that they had shown as babies to their parents (Waters, Merrick, Treboux, Crowell, \& Albersheim, 2000). However, attachment is also susceptible to change, especially in times of stressful life events. The same study found that $44 \%$ of the participants changed attachment classifications when negative life events were reported (Waters et al., 2000). These findings highlight Bowlby's notion that attachment is amenable to change over time; however, there is an underlying stability to the pattern.

Attachment styles in adulthood. Main and colleagues (1086) were the first to empirically research the idea that attachment styles endure throughout one's lifetime. Hazan and Shaver (1987) then attempted to classify adult romantic relationships using the same four styles originally designated by Ainsworth and her research team. More 
recently, Bartholomew and Horowitz developed the Relationship Questionnaire (RQ; 1991) and conceptualized adult attachment relationships as falling into four classifications: secure, fearful-avoidant, preoccupied, and dismissing-avoidant (see Figure 1).

Figure 1. Bartholomew \& Horowitz' (1991) model of adult attachment.

\begin{tabular}{clll|l|}
\multicolumn{2}{c}{} & \multicolumn{3}{c}{ Model of Self } \\
\multirow{3}{*}{$\begin{array}{c}\text { Model } \\
\text { of Others }\end{array}$} & Positive & Positive & Negative \\
\cline { 3 - 4 } & Negative & Secure & Preoccupied \\
\cline { 3 - 4 } & & $\begin{array}{l}\text { Dismissing- } \\
\text { Avoidant }\end{array}$ & $\begin{array}{l}\text { Fearful- } \\
\text { Avoidant }\end{array}$ \\
\cline { 3 - 4 } & &
\end{tabular}

Secure. These individuals demonstrate a positive model of the self and others. They feel a sense of worthiness and lovability and regard other people as accepting and responsive to their needs. This attachment style is characterized by low anxiety and a low avoidance of others.

Preoccupied. These individuals demonstrate a negative model of the self, but a positive model of others. They often desire contact with others as a means of gaining acceptance to mitigate their own sense of unworthiness and unlovability. This style is characterized by high anxiety and a low avoidance of others.

Fearful-Avoidant. These individuals demonstrate a negative model of the self and others. They feel a general sense of unworthiness and unlovability. They regard others as 
untrustworthy and rejecting of their needs. This style is characterized by both high anxiety and high avoidance of others.

Dismissing-Avoidant. These individuals demonstrate a positive model of the self, but a negative model of others. Though they have a sense of worthiness and lovability, they often protect against feared disappointment from others by avoiding close relationships. This style is characterized by low anxiety, but a high avoidance of others.

\section{The Significance of Relationships with Others}

Kohut, the founder of self-psychology, added to Bowlby's ideas by suggesting that relationships are needed to repair the self. This translates into less importance placed on what the parent does with the child, and more importantly, how the parent is with the child (Flores, 2001). However, when the infant's needs are not met or responded to, the individual may succumb to rage, psychological vulnerability, or depression.

According to Kohut, the child has three basic needs: grandiose exhibitionistic needs, idealizing needs, and twinship needs. Grandiose exhibitionistic needs refer to the need for mirroring, in which individuals feel that they are being seen for who they truly are underneath any facades. The second selfobject transference is idealization, which occurs when viewing someone with high regard so as to provide ideals, values, and principles. In attaining these three needs, the child creates a healthy sense of self and ego. Twinship needs, the third selfobject transference, are defined as the desire to be a part of a community, or larger system. The term twinship can also be referred to as a psychological sense of community (PSOC), the perceptions and experiences of belonging to a larger system (McMillan \& Chavis, 1986). Of importance are not only individual's relationships with others, but also their relationship with the system at large as the 
systemic group plays a major role in influencing the individual's behavior, personality, and self (Gold, 2012).

\section{Insecure Attachment as a Possible Pathway to Substance Abuse Problems}

Flores (2004) outlines a hypothesized theoretical model identifying the pathways by which poor attachment experiences contribute to SUDs (see Figure 2). The proposed model suggests that due to unmet developmental needs, mainly emotional needs, a fragmented sense of ego results. Unable to form a cohesive identity, affect regulation is impaired. This results in an inability to correctly identify emotions as well as control for them during times of high stress or turmoil. As would be expected, an inability to regulate affect is linked with a lack of internal resources to rely upon. This also translates into self-esteem, which is unable to develop without the self-object transferences of mirroring and idealization. Without any ability to turn inward, the individual develops an object hunger - meaning, a need for others to satisfy the lack of cohesive identity.

A psychological void that cannot be fulfilled by others results and the needs of the individual remain unmet. Guilt, shame, and anger ensue, as responses to an inability to fulfill one's own needs as well as a response to others and their inability to offer assistance. There may even be feelings of denial that one needs others, bringing individuals to seek gratification in things as opposed to relationships (Flores, 2001). To cope with these strong negative emotions, drugs and alcohol become one of many viable options to self-medicate the anxiety (Flores, 2004).

Substance use can be regarded as both a consequence of and a solution to insecure attachment styles. Insecure attachment styles in childhood share common themes of poor affect regulation resulting from a lack of maternal reflective functioning. Inconsistencies 


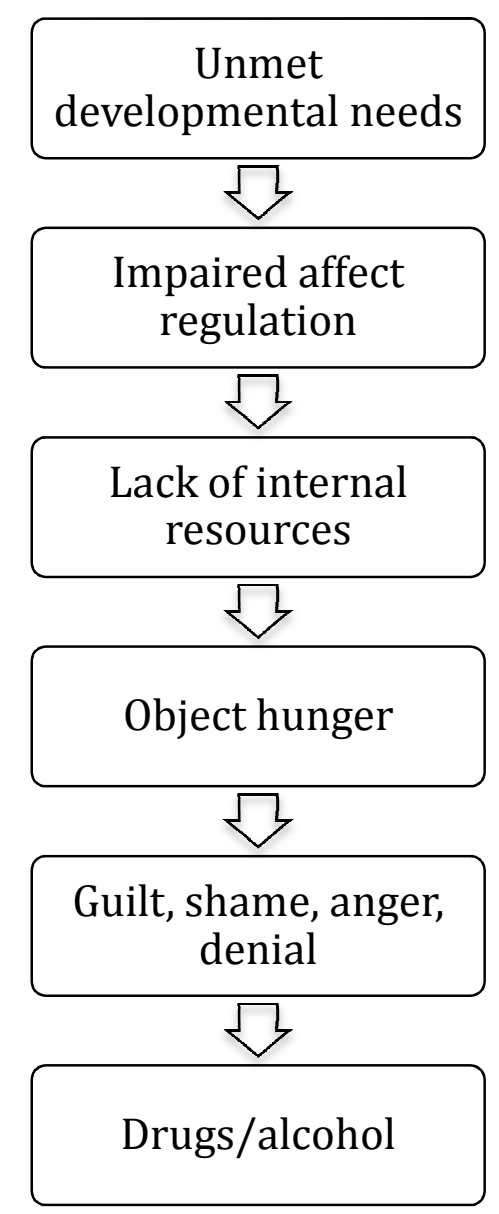

Figure 2. Proposed pathway by which attachment-related experiences lead to SUDs (adapted from Flores, 2004).

in how the maternal caregiver responds to the infant results in the propensity for one's adulthood to be filled with ambivalence, insecurity, and internal disorganization. As illustrated from the biological evidence for the innate need for attachment relationships, various negative consequences stem from the absence of or unhealthy connection with others. As such, SUDs can be conceptualized as a possible negative consequence of attachment-related deficits. 
Substance abuse also acts as a solution, a coping mechanism to address the negative consequences of their insecure attachment style. It provides a form of selfmedication by acting on the symptoms of poor attachment relationships, deficits in selfregulation, and internal disarray (e.g., discomfort with one's sense of self). Walant (1995) adds to this and proposes that addiction acts as a substitute for unmet developmental needs, such as attachment security. Unfulfilled attachment needs in conjunction with poor affect regulation creates a propensity for addiction. Much like the medication hypothesis of substance use development, addiction is seen as a way to repair the self and the various vulnerabilities and deficits that arise (Flores, 2004). In essence, it is believed that individuals attach to drugs as a substitute for interpersonal relationships.

Though there is strong theoretical support for the construct of attachment, the empirical support for attachment classification as a predictor of substance abuse problems specifically, remains limited.

\section{The Empirical Literature}

Given the theory described above, one can hypothesize that individuals with an SUD should be overrepresented in unhealthy attachment styles and underrepresented in secure attachment styles. The results of several studies are consistent with these predictions, although limitations exist when attempting to broaden the results to other populations of interest.

Caspers, Yucuis, Troutman, and Spinks (2006) conducted a longitudinal adoption study in which participants were administered the Adult Attachment Interview (AAI; George, Kaplan, \& Main, 1985), Semi-Structured Assessment for the Genetics of Alcoholism, and a questionnaire soliciting information about mental health care received. 
Results indicated that one's odds of receiving an abuse or dependency diagnosis increased three times for those classified as dismissing, preoccupied, or earned-secure (secure state of mind, but without a supportive relationship with at least one parent). Additionally, those individuals with dismissing attachment styles reported lower rates of participation in substance abuse treatment whereas individuals with preoccupied and earned-secure styles reported higher rates of involvement in treatment. The authors attributed this finding to the fact that attachment relationships undoubtedly influence one's chances of incurring a drug or alcohol dependency issue, as well as one's willingness to seek help for substance abuse/dependency issues (Caspers et al., 2006). Kassel, Wardle, and Roberts (2006) studied the effect of unrealistic expectations of approval from others, perfectionistic standards, vulnerability to distress, and selfesteem in a college student sample $(N=212)$. Participants were also asked to fill out an 18-item inventory on adult attachment dimensions based on a version of Hazan and Shaver's (1987) descriptions of the four attachment prototypes. As in Caspers et al. (2006), an anxious attachment style was associated with marijuana use $(r=.16)$ and alcohol consumption $(r=.22)$, though these correlations are relatively small. Furthermore, the authors found that dysfunctional attitudes and self-esteem were affected most by anxious attachment, thus contributing to drug use frequency. The authors concluded that a fear of abandonment, the "trademark" of anxious attachment, is the "most important aspect of insecure attachment in terms of predicting substance use" (Kassel et al., 2006, p. 1172). These findings should be regarded with caution, however, due to the cross-sectional nature of the study, limiting the ability to make interpretations 
about temporal precedence. Rather, it is safe to conclude that drug use, dysfunctional attitudes, and low-self esteem seem to be intertwined with insecure attachment styles. Allen, Hauser, and Borman-Spurrell (1996) determined that drug use could be predicted by attachment classification. The authors utilized two samples of adolescents $(N=142)$ that were recruited based on being a freshman in a local high school or having been recently admitted for psychiatric hospitalization. Those adolescents who were hospitalized were included only if they received a nonpsychotic psychiatric diagnosis (most diagnoses were oppositional defiant disorder, conduct disorder, or major depression). A hierarchical regression model was utilized to determine the predictive value of attachment style states of mind on drug use. Similar to other studies, the AAI and a coding system of nine scales assessing states of mind related to attachment classification were utilized. Demographic factors and several states of mind associated with the dismissing and preoccupied attachment styles were predictive of hard drug usage. The two states of mind contributing to drug use, with effects over and above the other variables included in the model, were: derogation of attachment $(\beta=.25, p<.05)$ and absence of idealization of mother and father $(\beta=-.26, p<.05)$. Combined, these two scales indicate that states of mind that tend to dismiss the impact or quality of one's attachment relationships are associated with drug use. A possible interpretation of these data is that individuals who are susceptible to drug use, or who use drugs to cope, can be characterized as having a perception of lacking attachment with others.

It is important to note that these studies are widely discrepant in terms of measures utilized, samples gathered, and hypotheses/analyses generated. In most studies, the samples were homogenous and limited in nature. For example, Allen et al. (1996) 
utilized a homogenous sample of high school adolescents and hospitalized adolescents without any psychotic features and Kassel et al. (2006) utilized an undergraduate sample. Findings may also be a function of using clinical samples, as in Allen et al. (1996), which would result in more extreme attachment style classifications. The use of clinical samples may also indicate that the impact of severe and chronic Axis I or Axis II disorders, as defined by the DSM-IV-TR, affects the association between drug use and attachment style thereby acting as confounding variables. Additionally, attachment measurement is complicated and multi-faceted. Although the Adult Attachment Interview (AAI; George, Kaplan, \& Main, 1985) is a widely used and well-validated measure, it requires one-onone semi-structured interviews. Due to time constraints with administration and scoring, shorter self-report measures are commonly utilized. As such, the inconsistency with measurements may also impact the generalizability of findings across multiple domains.

Understanding how attachment theory can contribute to the development of SUDs allows for an understanding of how individuals are likely to act and respond in future relationships. Attachment patterns have shown to be significantly associated with, and predictive of, mood symptomotology and personality disorders, with insecure styles resulting in higher rates of psychological disorders (Sroufe, Carlson, Levy, \& Egeland, 1999). In this capacity, substance use may be understood as a symptom of an underlying conflict, such as attachment disruptions or difficulty forming strong relationships with others (Morgenstern \& Leeds, 1993). If in fact attachment experiences play a role in the development of SUDs, then interventions can be developed to target those with insecure attachment. Identifying possible risk factors (e.g., anxious attachment) may bridge the gap between theory and research, and clinical practice. 


\section{Intersection of 12-step Recovery with Attachment Theory as a Pathway Out of Substance Abuse Problems}

The empirical literature indicates that attachment experiences may contribute to the development of SUDs. As such, interventions aimed at both the symptoms of the SUDs and improving prior poor attachment experiences might be considered ideal. One such intervention that has shown promise in ameliorating poor attachment experiences is 12-step recovery, which creates and fosters more optimal relationships. Twelve-step groups operate anonymously and offer support with an emphasis on sharing experiences through empathy and listening. Overarching principles, notably the 12 steps, guide members through the recovery process in groups that are operated by members for members. Underlying its basic suppositions, attachment theory concepts are at work. As Kelly and colleagues (2009) note:

Critical too will be to place these social mechanisms within a multi-level theoretical framework that describes how social changes influence change mechanisms at other levels (e.g., individual-psychological and neurobiological) and vice-versa, in what is most likely a reciprocal process that changes dynamically over time. (p. 249)

In this capacity, 12-step recovery intersects with attachment theory in offering a pathway out of drug abuse. In repairing attachment relationships through reciprocal and mutual relationships, it is possible, if not likely, that there are psychological, neurological, and biological changes that occur as a result, thereby transforming the individual's internal working model.

\section{Social Support as a Mechanism of Change in 12-step Recovery}


Though the exact mechanisms by which 12-step groups foster positive outcomes are unknown, research is beginning to hone in on the possible mechanisms of behavior change within such organizations (Kelly, Magill, \& Stout, 2009; Morgenstern \& McKay, 2007). Mutual self-help groups are associated with better substance-related outcomes in terms of maintaining long-term sobriety (Humphreys et al., 2004; Humphreys et al., 1994; Kaskutas, Bond, \& Humphreys, 2002; Moos, 2008; Schiff \& Bargal, 2000). Further, it appears that a primary mechanism of these groups is support-related, paralleling the concepts of attachment theory and its focus on relationships with others and the system.

One of the most rigorous empirical studies illustrating the effects of 12-step groups on substance-related outcomes is Project MATCH (Project MATCH Research Group, 1997). In this study, participants were randomly assigned to three professional treatment conditions: 12-step manual-guided therapy, cognitive-behavioral therapy, and motivational enhancement therapy. One year after treatment, the three groups were similar in terms of decreased usage of alcohol and increased days of abstinence; however, the 12-step treatment group was associated with more engagement in attending 12-step meetings as well as a maintained continuous abstinence. These effects were also seen at the three-year post-test, in which the 12-step group was better at maintaining continuous abstinence relative to the other two treatment groups. This study illustrates the possible long-standing effects of 12-step groups in treating SUDs. Consistent with this finding, researchers reviewing a large body of studies on 12-step recovery suggest that involvement in these groups can be considered evidence-based practices for substance use disorders (Humphreys et al., 2004). 
In Kelly et al.'s (2009) review of the mechanisms of behavior change in AA, they determined that there were three empirically supported arenas: common factor mechanisms, specific AA practices, and social/spiritual factors. More specifically, social support can be conceptualized along two dimensions: structural (e.g., group attendance, quantifiable number of relationships), and functional (i.e., the degree and quality of the support received) (Groh, Jason, \& Keys, 2008). In terms of structural social support, Kaskutas et al. (2002) showed that increasing AA-related support resulted in ongoing recovery. This type of social support may lend itself to self-efficacy (i.e., the belief that one can carry out a behavior successfully). Within 12-step recovery, self-efficacy often refers to one's ability to remain abstinent. This variable has been determined to be a mediator for some of the 12-step attendance effects (Maisto, Connors, \& Zywiack, 2000; Bogenschultz, Tonigan, \&Miller, 2006).

Humphrey's et al. (1999) indicated that friendship quality, or functional social support, partially mediated the relationship between 12-step involvement and substance use outcomes. As such, the substance of the relationship, in addition to the structure and type of relationship, lends itself to recovery-based practice and support. This indicates that helping relationships encountered in 12-step groups may aid individuals in repairing outside relationships (Groh, Jason, \& Keys, 2008).

Attachment theory may offer such an explanation for how the 12-step group fosters change and encourages reparation in the individual's relationships and within themselves. Simply put "addiction from an attachment theory perspective holds one basic and simple premise about treatment: until substance abusers develop the capacity to establish mutually satisfying relationships, they remain vulnerable to relapse and 
addiction" (Flores, 2004, p. 35). If Flores' speculation that corrective attachment experiences are necessary to thwart SUD relapse, 12-step groups are uniquely positioned to help individuals develop and refine mutually satisfying interpersonal relationships.

\section{Program Aspect of 12-Step Recovery}

Organizations such as AA and NA delineate recovery-based behaviors into two components: program and fellowship. The program aspect is the nature of the 12-steps, while the fellowship aspect refers to the social interaction of meetings, sponsors and sponsees, and social gatherings (Kelly, Magill, \& Stout, 2009).

Members identify the 12-steps as an essential feature of recovery. The steps follow a progression. In the first three steps, the individual comes to understand their own powerlessness and the power innate in some Higher Power. This culminates in a spiritual turning over of one's will to this Higher Power. In the fourth step, the individual is asked to sort out instances, and consequences, of their addictive behaviors. This is then shared with a sponsor (step five). Inherent in this sharing is the building of trust, rapport, validation, and understanding with another human being. This can be viewed as the start of the corrective attachment relationship. Above all else, this relationship is assumed to be safe, fostering a "safe haven" for the individual to explore his or her own sense of Self. This is continued into steps six and seven, as the individual is encouraged to create a deeper sense and awareness of their character, and identity. In steps eight through ten, the focus is on repairing relationships through acceptance of responsibility and directly addressing missteps. The final two steps act as maintenance steps, whereby the spiritual, emotional, interpersonal, and psychological aspects are incorporated into one coherent facet. 


\section{Fellowship Aspect of 12-Step Recovery}

This portion of the 12-step model includes more social concepts, which closely map onto attachment theory domains. It includes any form of social interaction relating to the group and its members. One of the premises of 12-step recovery is a focus on changing relationships, which may result in changing attachment style (Smith \& Tonigan, 2009). Focusing on one's home group and relationships with others, allows individuals to feel a sense of belonging in the context of a community. Not only does one build attachments to other individuals in the group, but also the group itself becomes an object with which the individual can attach.

Smith and Tonigan (2009) mailed a survey to individuals participating in 12-step treatment. Participants were included in the analysis if they had attended at least 30 AA meetings in their lifetime (and if they attended more AA than other 12-step meetings), resulting in a sample size of 158 . The attachment measure was amended from Hazan and Shaver's (1987) design of three-items assessing for Ainsworth's original three attachment styles (secure, avoidant, and anxious-ambivalent) by altering the statements to reflect preAA and post-AA attachment. Participants were also asked to answer four questions regarding length of involvement in 12-step groups, frequency of attendance within the past 3 months, average frequency of attendance per month, and relative importance of belief in a Higher Power. Regarding practices, participants were asked about the frequency of talking to members outside of group, length of time having a sponsor, and degree of working the steps.

The authors found that AA affiliation was associated with gains in subjective ratings of attachment security. Furthermore, individuals' reports of anxious and avoidant 
styles significantly declined from pre-AA to post-AA involvement $(d=.81)$. The finding supports the conclusion that 12-step groups encourage safety and security within the context of the development of healthy relationships. In fact, the decrease in anxious attachment ratings means that there is less worry about others' love or fear of abandonment from others. The decrease in avoidant attachment ratings indicates that there may be less worry about becoming close to others and similarly, trusting others is enhanced (Smith \& Tonigan, 2009).

The authors extracted two factors in a confirmatory factor analysis of the assessment battery: exposure and practice of AA behaviors. The exposure factor included items such as frequency of attendance and average number of meetings attended across a one-year period. The practice factor included items such as frequency of talking with 12step members outside of meetings, length of time having a sponsor, and number of times working the steps (Smith \& Tonigan, 2009). Regression analyses indicated that practice, not exposure, accounted for changes in attachment style due to the process of engaging and interacting with others and not merely attending meetings (Smith \& Tonigan, 2009). The authors suggest that future studies incorporate the four different attachment styles and include additional items that capture AA involvement. Additionally, as a crosssectional study, this study has some limitations in that participants were asked to retrospectively reflect on their attachment style prior to attending AA. This highlights the necessity of future research utilizing a longitudinal design method so as to assess more accurate linear relationships.

Understanding drug abuse from an attachment theory perspective means that individuals are essentially attaching to illicit substances instead of relationships. Relying 
on substances allows the substance user to abolish feelings of embarrassment or shame from needing someone. Therefore, from an attachment theory perspective, the premise of the 12-step group is to encourage members to attach to new prosocial and emotionally supportive relationships, and relinquish any old attachments to drugs.

The group as a secure base and transitional object. Narcotics Anonymous, as well as other 12-step programs, stress the importance of joining a home group. Home groups offer the opportunity for individuals to become strongly involved with its network of individuals and offers the potential for an intimate setting in which members can relate with one another safely and effectively. Essentially, a community is formed. It is possible that the group becomes a secure base, or healthy object, because it allows individuals to take more interpersonal risks within the context of a safe environment. This is exemplified in healthy exploration of one's environment as indicated in the "Circle of Security" (2006) resulting in a stable sense and understanding of oneself. In a recent study on the possible effects of recovery-related practices on indicators of psychological well-being in a sample of NA members, the most robust recovery-related predictor was comfort at one's home group, which offered significant independent prediction of self acceptance, personal growth, purpose in life, and positive relations with others over and above markers of substance use severity, neuroticism, and other recovery practices (DeLucia et al. 2012). The notion of comfort at one's home group may extend to attachment theory's concept of a secure and safe holding environment. Further, attachment theory argues that comfort is achieved through the culmination of safe and fulfilling relationships that provide nurturance and mirroring. This feeling of security is 
then extended to other situations and environments, resulting in higher levels of psychological well-being across a variety of contexts.

The building of relationships with group members is symbolically representative of the young child forging outside relationships with peers. Part of healthy ego development, this feat allows the child to explore friendships outside of the nuclear family and to extend the internal working model to other situations. Similarly, the group offers a different internal working model and also inherently allows for the model to be applied to the individual relationships of group members. This can also be a healthy replication of the mother/infant relationship, replacing poor maternal attunement with appropriate reflective functioning by the group. The group, therapist, and characteristics of the relationships are internalized, leading to the rebuilding of ego structure, and ultimately, they pave the way for future intimate and mutually fulfilling relationships to be formed in lieu of the addiction.

Psychological sense of community. The term "community" can denote either geographical or relational connections. The relational component consists of the human connectedness portion and does not refer to location (Gusfield, 1975). Both degrees of community exist within the 12-step framework. Referring to the nature of the home group, there is a true connection that develops with members of the same region belonging to a sub-community. Community also develops in a relational context in which members join and unite to share experiences. A strong sense of community has been correlated with problem-focused coping behaviors (Bachrach \& Zautra, 1985). This is supported by research findings that those who attend AA meetings are more likely to utilize approach coping (an active style), rather than avoidance coping (Humphreys, 
Finney, \& Moos, 1994). Bachrach \& Zautra (1985) discovered that an underlying pathway was present - approach-focused coping led to community involvement, which further led to a sense of perceived control with external threats.

McMillan and Chavis (1986) propose a theory of a psychological sense of community that encompasses four components: membership, influence, reinforcement, and shared emotional connections. These four dimensions can be used to assess for one's perception of involvement in the group, feelings of belonging, and subsequently, selfefficacy as a group member.

Membership. This refers to the sense of belonging felt as being part of a group. Boundaries evolve between those who belong and those who do not. In keeping out nonmembers, it protects those who are involved and provides them with emotional safety (McMillan \& Chavis, 1986). This replicates the attachment relationship in creating a safe holding environment for the individual where they can feel comfortable and secure. Members are actively encouraged to introduce themselves as addicts, thereby identifying themselves as one of the community. In proclaiming and working for membership, this has a two-fold outcome. Not only does it empower the individual with a sense of accomplishment, but it also creates a more meaningful and valuable membership (McMillan \& Chavis, 1986).

Influence. There exists a two-way relationship between the individual and the group: (1) of the individual over the group, and (2) of the group over the individual (McMillan \& Chavis, 1986). Again, relating to attachment theory is the nature of the bidirectional relationship. Feeling as though one exerts some control over their environment is a necessary and healthy developmental achievement. The back-and-forth 
reciprocity that occurs leaves individuals with the capacity for conformity to values without sacrificing personal freedoms.

Inherent in the make-up of 12-step recovery groups is both an attitude of being helped by as well as helping others. For example, 12-step groups teach members how to effectively care, empathize, and express concern for others without overly investing themselves, as in co-dependency (Flores, 2001). Intuitively, this fits with the 12-step model. Of the 12 steps, namely Steps 5, 8, 9, and 10, most incorporate intra- and/or interpersonal components, illustrating what may be considered the underpinnings of attachment theory. The steps advocate for an acceptance and responsibility of one's behaviors and empathy for others' thoughts and feelings. In collaboratively relating with others, the fragmented self gains the opportunity to become more coherent, thereby changing the individual's attachment style.

In fact, research indicates that giving help is associated with greater mental health as compared to receiving help (Schwartz, Meisenhelder, Ma, \& Reed, 2003; Roberts, Salem, Rappaport, Toro, \& Seidman, 1999). In fact, it has also been indicated that in helping others, people benefit as much as, if not more, than those who only receive help (Schwartz \& Sendor, 1999, Zemore \& Pagano, 2008).

Qualitative analyses of focus group participants in NA recovery indicated that most members felt that service work enabled them to transition from selfish to selfless (DeLucia et al., 2010). This is one way in which 12-step groups offer an ancillary component that would otherwise be unattainable in typical one-on-one psychotherapy. While individuals suffering from SUDs do in fact need to rely on others and form stable attachments to others, the reciprocity and mutuality component also needs to be 
considered. It may be that helping behaviors, in addition to receiving one's own help, may create a sense of self-efficacy and confidence. Engagement in helping behaviors within 12-step work leads to higher rates of abstinence (Magura et al., 2003), and additionally, lower rates of relapsing (Pagano, Friend, Tonigan, \& Stout, 2004).

One study found that individuals who participate in community service through the designing and implementation of their own projects had lower rates of discipline problems and social alienation than those who were assigned to a control condition (i.e., no community service). Furthermore, when participants were asked to terminate their project, feelings of alienation increased (Calabrese \& Schumer, 1986). This study speaks to the concept that humans are motivated to engage with others through interaction and connection. There is not only a need for others to offer support and love, but a desire to fulfill those needs in others as well.

Twelve-step groups provide various avenues for individuals to both receive and fulfill helping roles. For example, there are service roles such as the coffee bar, greeting individuals, setting-up and putting things away. These service roles allow helping behaviors to be directed to both individuals (e.g., serving coffee to members) as well as to the group as an entity (e.g., room maintenance).

Members are also encouraged to act in helping roles within the overall organization. Within the AA-approved service pamphlet, several ways in which members can help the General Service Office (GSO) are listed (e.g., stay informed, choose a general service representative to act as liaison between the group and GSO) (Alcoholics Anonymous World Services, 2005). Tradition one, which states that members are a "small part of a great whole" (Alcoholics Anonymous World Services, 2005, p. 44), 
speaks specifically to this notion of members acting within a helping role for the group as a whole first and helping the individual second. This message is further carried into world service. Simply put, 12-step groups create a variety of helping roles for the individual, group, and regional or central offices to partake in. Helping is seen as a central tenet of the group.

Another mechanism by which helping is established is through the sponsor and sponsee relationship (Zemore \& Pagano, 2008). Again, the nature of 12-step groups is that it establishes a means by which the member can reach out for help. Once the ideals and values are internalized through working the 12 steps and repairing the attachment pattern, the sponsee is enabled to become a sponsor him or herself. Research has found that for those individuals who had been AA sponsors, there was a $91 \%$ remission rate in a 10-year follow-up study (Cross, Morgan, Mooney, Martin, \& Rafter, 1990).

Reinforcement. The third domain within the definition of psychological sense of community is the integration of needs, which is also referred to as reinforcement (McMillan \& Chavis, 1986). In joining together on the basis of similar shared values, group cohesiveness is solidified. This reinforcement phenomenon, or fulfillment of needs, is seen within the attachment relationship. Providing emotional nurturance and understanding within an empathic framework reinforces the belief that the individual's needs can and will be met. Reinforcement also depicts the helping relationship. As McMillan \& Chavis (1986) state, "People enjoy helping others just as they enjoy being helped, and the most successful communities include associations that are mutually rewarding for everyone" (p. 16). 
Shared emotional connections. Lastly, shared emotional connections are the collective experiences of the group. This may be an actual experience that all group members shared in together, or it can refer to separate experiences with a unified theme. The primary premise is that all members are able to identify with the shared history (McMillan \& Chavis, 1986). In fact, social networks have been shown to be a mechanism of action for Alcoholics Anonymous (Kaskutas et al., 2002; Groh, Jason, \& Keys, 2008).

Mutual self-help organizations have several ideological values, or features that originate from the shared history. In fact, because of the strong ideologies, 12-step programs may have advantages over other self-help or therapeutic groups (Schiff \& Bargal, 2000). The premise guiding these groups is that members come together to work on a communal problem in a reciprocal fashion. Leadership is self-directed, which allows individuals to develop a sense of control of their own destiny (Humphreys, 2004). This is, in part, an aspect of safe exploration of one's environment. Through sharing experiences and fostering reciprocal relationships, the attachment relationship is afforded the opportunity to repair itself. Further, by focusing on self-directed leadership, the individual is encouraged to safely explore positions of power, helping, and autonomy. Every member is seen in the light of having an asset to contribute. This resembles the safe and secure environment created in a secure parental-infant attachment pattern.

In having these shared experiences, members gain insight into their multi-faceted identities. This may even aid them in constructing a new narrative (Humphreys, 2004). Relating to Kohut's theory, this may be the quintessential example of mirroring - a reflection of who one is and what comprises their true identity. As such, it helps to contribute to the development of a new internal working model. It becomes a story that is 
created by the individual in regards to their own identity and experiences, thereby replacing the old and maladaptive one. This new model replaces past experiences and becomes the prototypical recovery story that is shared with newer members just beginning their journey to recovery. In 12-step organizations, individuals will often idealize the organization as a whole and internalize the morals and maxims passed down from their sponsor. Flores (2004) also suggests that the selfobject transferences of efficacy (feeling as though one has a positive effect on others), self-delineating (the formation of one's individual self without fear of or loss of attachment relations), and witnessing (an emotional understanding of wrongdoings and transgressions) are displayed in AA and NA membership.

Summary of PSOC. The theories and mechanisms of psychological sense of community have substantial overlap with those of attachment theory. The constructs of a safe and secure environment (or relationship) increase the individual's propensity for building self-esteem, affect regulation sills, and ultimately, fosters the enhanced development of the internal working model. Furthermore, a psychological sense of community is innate in the development of 12-step organizations. Fellowship, as it is referred to in AA and NA, is somewhat synonymous with the constructs outlined by McMillan and Chavis (1986). Kelly and colleagues state:

AA itself, at least in its core texts, may have ignored explicating perhaps its most potent influence on individuals' recovery - that of social group dynamics in the AA meeting, the broader fellowship, and the expression of support that can be healing to many. Explicit in its meeting preamble, the '...fellowship of men and 
women who share their experience, strength, and hope with each other...' may be the most critical element of AA's effectiveness. (2009, p. 252)

Membership, member's influence over others and the group, reinforcement for following group values, and the sharing of communal emotional experiences are at the essence of 12-step recovery.

Affect regulation and self-esteem. Continuing with the fundamental suppositions of fellowship within 12-step recovery, AA and NA membership provides tools and skills for developing affect regulation. Due to the lack of attachment experiences, the child also suffers from a dearth of exhibitionistic, twinship, and idealizing needs necessary for healthy ego formation. Subsequently, individuals fail to develop self-esteem, leaving them to yearn for others' esteem. AA and NA fulfill this need for others' regard and aid the individual in transitioning from an attachment to drugs to an attachment to the group or other members.

Secure attachments lead to the presence of self-regulatory behaviors and capacities. An open feedback loop develops in which emotions and neurophysiology are intertwined (Ormont, 2001). Along with this, Schechtman and Rybko (2004) found that those with secure attachment styles had higher incidence of self-disclosure as compared to those with insecure attachment styles. Additionally, having a secure attachment style was associated with opening-up earlier in the group process, as opposed to later on, when compared to those with more insecure attachment styles (i.e., avoidant, anxiousambivalent).

DeLucia, Bergman, Bruder, \& Formoso (2010) found that focus group participants were able to identify three outcomes stemming from involvement in the 
recovery process, one of which was creation of an ideal self. Additionally, within the same study by DeLucia and colleagues (2010), participants described a shift from selfishness to selflessness in their movement through recovery. This illustrates the underlying process of internalizing the group's ideals thereby resulting in a stronger and healthier attachment style. According to Kohut, an ideal self can only be created once others (or as he explained, parents) are idealized. This allows for the transmission of skills, such as affect regulation, or emotion regulation, which involves self-processes of recognizing, understanding, and effectively managing one's emotions. By nature, once the skill-set is in place and fully internalized in the individual, there will be less of a dependent need on external forces (e.g., drugs or alcohol) to mediate feelings (Flores, 2001). Twelve-step groups may serve the role as the idealized parent, in that members can idealize the group, its writings, and individual members and their sponsor.

\section{Integrative Conclusions}

Attachment theory may be a possible pathway to the development of substance abuse problems. Attachment begins in infancy and creates the basis for one's ability to regulate affect, form an identity, and develop an interpersonal style characterized by reciprocity. As infants progress developmentally, attachment becomes reciprocal in nature, resulting in close affiliative relationships that ensure a collaborative, fulfilling, and mutual survival. Should this relationship be disrupted, research indicates that individuals are at risk for developing a multitude of internalizing and externalizing disorders (Kennedy \& Kennedy, 2004; Lyons-Ruth et al., 1993), insecure attachment, and even an insecure identity. Kohut, the founder of self-psychology, adds to this by suggesting that relationships are needed to repair the self. 
Walant (1995) proposes that addiction is a substitute to cope with developmental needs previously unmet in childhood (e.g., attachment). Without proper or appropriate parenting, the child may be at risk later in life as they fail to develop the appropriate and necessary skills. This pattern of effects could be subsumed by Sher's (1991) devianceproneness submodel. A significant number of individuals presenting for SUD treatment have an insecure attachment style (Flores, 2001). In essence, individuals attach to drugs as a substitute for interpersonal relationships.

It is interesting to note that the interpersonal connections facilitated by 12 -step recovery programs (e.g., connection with a sponsor, connection with fellow members) can be conceptualized as attachment-like experiences. The 12-step group focus on changing relationships intrapersonally, interpersonally, and with the group may create healthy and adaptive relationships thereby also changing attachment style. The group itself becomes an object with which the individual can attach.

For example, attachment theory refers to the connections people have with others, and how those connections impact their self and identity resulting in long-lasting benefits. The 12-step approach to recovery is based on similar principles - people coming together to help and foster recovery for one another through social, practical, and emotional support. In this capacity, 12-step recovery is focused on abstinence, as well as the creation and development of healthy, more adaptive, interpersonal relationships. Presumably, individuals enter recovery with a fractured sense of self due to their significant substance use histories and comorbid disorders. The organization's values and core ideologies are centered on support, nurturance, and identity building. These values are accomplished through several avenues: home group involvement and receiving help 
from and helping others (micro-level interpersonal relationships). Further, it is accomplished through a psychological sense of community within the home group as well as the organization as a whole (macro-level interpersonal relationships). The nature of 12-step recovery is such that person-to-person interactions are first formed and accomplished through peers, the sponsor-sponsee relationship, and social outings. In early recovery, it is probably true that individuals receive more help than they give - an observation echoed by long-term members of NA in focus groups (DeLucia et al., 2010). There are also opportunities for newer members to serve other members and the fellowship more generally (e.g., by making coffee). These behaviors can easily be viewed through an attachment lens in that in building a secure relationship, the infant is encouraged to take as much love and bonding necessary so that he may explore his environment. This constant taking, and subsequent feeling of being satisfied, is then internalized and thus enables the individual to give in an adult relationship.

Howes (1999) defined three criteria to delineate attachment figures outside of the family. These include physical and emotional care, a stable presence, and an emotional investment. In theory, twelve-step recovery groups accomplish these three goals wholly. For example, the group provides a physical and emotional place of security, in which anonymity is protected, respect is delivered, and particular focus is given to welcoming each and every member into the group. The presence of the group is enduring, even if the individual members are not. As such, individuals can return to the group and find that though the members of the group have changed, the content and process is similar. Lastly, an emotional investment on the part of the group (and other members) is often transmitted to the individual, most notably seen in the sponsor-sponsee relationship. 
There appear to be myriad ways in which 12-step groups promote these three facets of the attachment-figure relationship. It is worth noting that support received from others as well as more active and adaptive coping skills are two mediators that have been implicated in understanding the mechanisms of 12-step recovery-both of which can be related to attachment-related constructs as described above.

These inter-related concepts are perhaps best integrated by the theory of psychological sense of community (PSOC) articulated by McMillan and Chavis (1986). Beyond prevailing conceptualizations of social support, PSOC seems to be more multidimensional in that it can capture the bidirectional influence between individual and other individuals, as well as the collective fellowship. The construct of PSOC has four components that it measures: membership within the group, influence over the group as well as the feeling that one matters to the group, fulfillment of needs from group membership, and shared emotional connection which is perceived warmth and understanding among members (McMillan \& Chavis, 1986). As such, PSOC may tap into the strong connections to the community as well as the cluster of individuals.

In the present paper, attachment theory was discussed as it can be used to explicate the etiology of SUDs indicating that an insecure attachment style may increase the propensity for drug abuse. Attachment theory can also be utilized in a context of attempting to understand the mechanisms of change that exist within 12-step recovery groups. Several themes were identified within 12-step recovery that map onto the theory of attachment (e.g., the home group as a secure base, psychological sense of community, and fostering a burgeoning self-esteem). As such, altering one's attachment style through 
social relationships, emotional understanding, and fulfilling interpersonal situations, may result in favorable psychosocial outcomes for members of 12-step organizations.

\section{Project Goals and Contribution to the Field}

The current study has five primary goals:

1. To show that within the NA sample, longer abstinence durations will be associated with more secure attachment styles. More specifically, individuals with a fearful-avoidant style will have the lowest average abstinence duration; individuals with secure attachments will have the highest average abstinence durations; and individuals with dismissing-avoidant and preoccupied styles will fall in the middle with respect to abstinence duration.

2. To show consistency in preferred attachment style across both nominal and ordinal scales. This is captured by asking participants to not only select the attachment style statement they best identify with, but by also asking participants to rate on a Likert scale the degree to which each attachment category best fits their style. It is expected that those who categorize themselves as secure will also rate themselves highly on the scale for a secure attachment style and rate themselves lower for the remaining three styles. This is expected to be similar across all three categories (i.e., fearful-avoidant individuals will rate themselves high on the scale more so than the other three categories, and so on).

3. To examine various recovery-related and social-support predictors of attachment. The primary predictors of interest will be recovery-related variables (home group comfort, home group socialization, home group service, connection with one's sponsor, number of sponsees, years of NA-related service, frequency 
of past year NA meeting frequency, number of times working the 12 steps), social support-related variables (number of people providing emotional and practical support within and outside of the recovery network, perceived helpfulness of the emotional and practical support received from those within and outside of the recovery network), and psychological sense of community. Age and sex will also be entered into the models as demographics. The following covariates will also be included in the model: unrealistic favorable presentation, neuroticism, and substance use severity. It is hypothesized that the set of primary predictors will offer significant prediction of attachment—over and above the set(s) of demographics and covariates.

4. To examine whether secure attachment predicts psychological well-being. The same demographics and covariates will be entered into the model: personality traits, social desirability, substance use severity, age, and sex.

5. To examine whether positive attachment experiences mediate the association between positive interpersonal recovery experiences (e.g., connection with other members, connection with sponsors, quality of home group relationship) and psychological well-being (e.g., autonomy, positive relations with others, selfacceptance). Again, the same demographics and covariates will be entered: personality traits, social desirability, substance use severity, age, and sex. The current study has several implications. In understanding the pathways by which substance abuse may be ameliorated, interventions and preventative programs can be implemented. Understanding the intersection between 12-step groups and attachment style, social relationships, emotional understanding, and fulfilling interpersonal 
situations, may help in choosing what treatment might be most effective for a particular individual. Or, in a similar fashion, it may inform future interventions by ensuring that the attachment relationship and sense of community are targets of treatment.

The theoretical literature for both psychological sense of community and attachment suggests that deeper and more meaningful connections with others are necessary for healthy development. If in fact attachment disruptions, or lack of perceived connection with others, are at least partially responsible for the development of substance abuse, then it stands to reason that introducing interpersonal recovery practices may be one such avenue to remediation. While the content of NA and other 12-step recovery organization is paramount, it may be that connection with others, a sense of belonging to a community at large, and forged bonds with those sharing similar backgrounds contribute, or underlie, the outcome of psychological well-being. Exploring the various pathways by which 12-step recovery may create positive growth and change for individuals, may allow for other treatment modalities to target some of the same concepts. Further, it may serve to function as a model or template for how other disorders or pathology possibly resulting from attachment disruptions may benefit from a treatment modality that stresses and fosters interpersonal connectedness. 


\section{Method}

\section{Procedure}

Participants were recruited through two avenues: 1) initial recruit persons, and 2) posting a recruitment flyer to a social networking site dedicated to 12-step recovery (www.intherooms.com). In order to participate, individuals were required to be 18 years or older and to have a minimum of one year's membership in Narcotics Anonymous (NA). Participants were directed to an online survey website which included the Informed Consent; an array of measures assessing constructs such as psychological wellbeing, social support, substance use severity, etc.; and a short demographics questionnaire. Initial entry into the study was stratified by abstinence duration and sex resulting in eight strata: women with 1-5 years clean, women with 6-10 years clean, women with 11-15 years clean, women with 16 or more years clean, men with 1-5 years clean, men with 6 to 10 years clean, men with 11 to 15 years clean, and men with 16 or more years clean. Upon completing the survey, instructions were given to contact the Principal Investigator to receive a $\$ 30$ e-gift card.

\section{Participants}

Participants ranged in age from 22 to 64 years old $(M=45.68, S D=10.66)$. The percentage of females was only slightly higher than that of males (52.7\% female). The sample was predominantly composed of those who identified as Caucasian (79.5\%), with the remaining portion of individuals identifying as African American (10.7\%), Latino (3.6\%), Asian American (2.7\%) and Other (2.7\%). Abstinence duration ranged from a minimum of one year to 33 years in recovery $(\mathrm{M}=12.05, \mathrm{SD}=8.00)$. Eighty-nine 
percent of the sample endorsed current membership in a home group, and $100 \%$ of the sample reported that they currently had a sponsor.

\section{Measures}

Demographics. Sex and age were included in analyses as covariates. Other demographic factors such as ethnicity, educational status, and marital status were also provided by participants, but were eliminated from analysis due to nonsignificant correlations with the outcome measures and the reduced sample size that resulted from non-response.

Abstinence duration. Abstinence duration, in years, was computed by subtracting the respondent's self-reported date of last substance use from the interview date.

Substance use severity. A marker of substance use severity was computed by averaging the z-scores of two items: (a) earliest age of any use of 12 substances; and (b) count of 12 substances for which participants endorsed problematic use (reverse scored).

Unrealistic favorable presentation. Unrealistic favorable presentation was measured by the Lie subscale of the Minnesota Multiphasic Personality Inventory Second Edition (MMPI-2; Butcher et al., 2001). The scale consists of 15 true/false items (true $=0$, false $=1$ ). The items are then summed together; higher scores reflect higher levels of unrealistic favorable presentation.

Neuroticism. Neuroticism was measured by the Neuroticism subscale of the Big Five Inventory-10 item short form (BFI-10; Rammstedt \& John, 2007). The scale consists of two items: "I am relaxed, I handle stress well" (reverse scored) and "I get nervous easily." The shortened version is highly correlated with the 9 -item original scale $(r=.85$ - 
.88; John, Donahue, \& Kentle, 1991). Items were assessed using a 5-point response scale ranging from 1 (disagree strongly) to 5 (agree strongly). Items were moderately correlated, $r(112)=.42, p<.001$.

Home group comfort. Home group comfort was assessed by averaging two items: (a) "I feel very comfortable at my home group"; and (b) "I have a strong connection to others at my home group" $(r(100)=.630, p<.001)$. Response options for these items ranged from 1 (never/almost never) to 4 (always/almost always). The home group can be regarded as a secure base, or holding environment, for members in 12-step groups.

Home group socialization. Home group socialization was assessed by averaging two items: (a) "I socialize with home group members before my home group meeting" and (b) "I socialize with home group members after my home group meeting," $r(100)=$ $.272, p<.001$. Response options for these items ranged from 1 (never/almost never) to 4 (always/almost always).

Home group service. Home group service was assessed by the question "I do service work at my home group." Response options for these items ranged from 1 (never/almost never) to 4 (always/almost always).

Connection with one's sponsor. A measure of connection to one's sponsor was calculated by averaging the response ratings to eight items were selected from a larger questionnaire. This variable includes items such as: I seek my sponsor's guidance on lots of issues related to my life; I consult my sponsor before making major life decisions; I can count on my sponsor when I really need him/her; my sponsor is trustworthy; my sponsor is supportive; my sponsor is loving, my sponsor is compassionate, and my 
sponsor is a good listener. Response options for these items ranged from 1 (disagree strongly) to 5 (agree strongly). Cronbach's alpha was .863 .

Number of sponsees. The number of sponsees worked with was assessed by the question, "How many sponsees have you assisted in working ALL of NA's 12 steps?"

Years of NA-related service. NA-related service was assessed by adapting NA's World Pool Information Form (Narcotics Anonymous World Services, 2012), a form the organization uses to assess member service involvement. Respondents reported on the number of positions they held across service levels (e.g., home group, area) and number of years of service in these various positions. Total number of years of NA service was computed.

Frequency of past year NA meeting attendance. Past year NA meeting attendance was assessed by the item, "In the past year, how often did you attend NA meetings?" Response options ranged from 0 (never) to 8 (6-7 times per week).

Number of times "working” the 12-steps. Number of times of completing or “working" the 12-steps was assessed by the item, "How many times have you worked NA's 12-steps with the assistance of an NA sponsor?"

Social support-related predictors (Appendix A). These predictors sought to measure the quantifiable number of people who provide practical and emotional support, both from individuals within recovery as well as outside of the 12-step recovery organization. Further, the perceived quality, or helpfulness, of each type of support was also reported using the following response scale: I have not received emotional support from people in recovery, not at all helpful, slightly helpful, moderately helpful, and very helpful. 
Relationship Questionnaire (RQ; Bartholomew \& Horowitz, 1991). This selfreport instrument is designed to assess adult attachment within the four styles. Participants are given a multiple-choice question with four options containing blurbs that depict a particular attachment in which they are asked to select the style that best describes or is closest to the way they perceive themselves. The second part of the questionnaire directs participants to rate each of the styles by indicating how well or poorly each description corresponds to their relationship style. This rating is based on a Likert scale $(1=$ disagree strongly to 7 = agree strongly $)$.

Due to the two dimensional nature of the questionnaire, it allows for an attachment style to be garnered based off of the participant's a) self-reported identification of their style; and b) their self-reported rating of how well it fits their style. Researchers then are able to categorize the individual's attachment style by using the style that is most highly rated on the Likert items (Stein et al., 2002). Internal reliability for this measure cannot be determined due to the limited number of questions (Hofstra, 2009).

\section{Psychological Sense of Community (PSOC; Sarason, 1974). Psychological} sense of community was measured using an amended version of Sarason's (1974) 24item scale. Questions are centered around one's sense of feeling that they belong and being able to depend on a community at large. Some authors have found support for a four-component model (McMillan \& Chavis, 1986), while others have supported a three component model (Proescholdbell, Roosa, \& Numeroff, 2006). For each item, respondents are asked to use the following scale: none, a little, some, a fair amount, and a great deal. The proposed factors are identified as: 
Membership. Membership is one's subjective feeling of belonging to the group (e.g., "How often do you feel that you are a member of the community?") ( $\alpha=.884)$.

Influence. Influence refers to the feeling that one has an affect on and is affected by the group (e.g., "How much do you feel able to influence the actions, thoughts, and feelings of other community members?", "How much do other members influence your thoughts and actions?") ( $\alpha=.813)$.

Fulfillment of needs. Fulfillment of needs is the feeling that one's needs will be met through membership in the group (e.g., "How often do you feel that you can depend on other members?") $(\alpha=.843)$.

Shared emotional connection. Shared emotional connection refers to feelings of warmth and understanding among group members (e.g., "In general, how much of a sense of camaraderie do members feel with each other?") $(\alpha=.829)$.

Porescholdbell, Roosa, and Nemeroff (2006) determined that amongst the three factors that remained after a confirmatory factor analysis (Influence, Shared Emotional Connection, and Fulfillment of Needs/Belonging), alpha coefficients ranged from .82-.87. In the current data set, correlations among the four subscales ranged from .229-.628.

Psychological Well-Being (Ryff, 1995). This 54-item instrument has six subscales designed to measure positive psychological functioning. Each question contains a 6 -point response scale $(1=$ strongly disagree to $6=$ strongly agree $)$.

Self-acceptance. Self-acceptance is the tendency to have a positive attitude about one's self (e.g., "I like most aspects of my personality"; "When I look at the story of my life, I am pleased with how things have turned out") $(\alpha=.855)$. 
Personal growth. Personal growth is a sense of one's growth toward selfimprovement (e.g., "I think it is important to have new experiences that challenge how you think about yourself and the world"; "I have a sense that I have developed a lot as a person over time") $(\alpha=.772)$.

Purpose in life. Purpose in life refers to one's derived sense of meaning in life based on beliefs (e.g., "Some people wander aimlessly through life, but I am not one of them"; "I enjoy making plans for the future and working to make them a reality") $(\alpha=$ $.749)$.

Positive relations with others. A positive relation with others is the extent of one's relationships with others characterized by trust, security, and emotional fulfillment (e.g., "Maintaining close relationships has been difficulty and frustrating for me" - reverse scored; "I enjoy personal and mutual conversations with family members or friends") ( $\alpha$ $=.644)$.

Autonomy. Autonomy is the extent of one's feelings of self-sufficiency (e.g., "I have confidence in my opinions, even if they are contrary to the general consensus"; "I judge myself by what I think is important, not by the values of what others think is important") $(\alpha=.738)$.

Environmental mastery. Environmental mastery is the extent of one's feelings of mastery over their environment (e.g., "I do not fit very well with the people in the community around me" - reverse scored; "I have difficulty arranging my life in a way that is satisfying to me" - reverse scored $)(\alpha=.811)$.

Sponsor-involvement and home group-involvement questionnaire. These included items that related specifically to one's emotional relationship with their sponsor. 
These items attempted to capture the quality of the relationship and the emotional fulfillment it lends to members. Participants were asked to read statements about their sponsor and rate the extent to which they agreed $(1=$ disagree strongly to $5=$ agree strongly). For example, participants were asked to rate the degree to which they believed that their sponsor was trustworthy, supportive, loving, compassionate, a good listener, and nonjudgmental. Participants were also asked to report the extent to which they sought guidance on issues related to life, consultation on life decisions, and whether their sponsor had encouraged the cultivation of their own understanding of recovery. Reciprocity was also measured through the question of whether participant's believed that their sponsor had come to them to seek advice on issues. 


\section{Results}

\section{Overview}

The analyses progressed in several stages. First, for each attachment category, differences in means across the Likert-scale items that assess the degree to which each style corresponds with one's overall style were evaluated with one-way ANOVAs.

Second, a series of single-predictor omnibus multinomial logit models were estimated to examine the univariate associations between the predictor variables and attachment groups. Cohen's d's are also provided for the pairwise contrasts.

Third, a series of hierarchical models were conducted to determine each predictor's relative contribution to the overall model. A demographics block and a covariates block were created. Each predictor was tested individually to determine if it contributed variance over and above the demographics and covariates. If a significant change in $\chi^{2}$ occurred, the variable was kept for later analyses. Those variables that were nonsignificant were excluded from further analysis.

Fourth, the odds ratios were calculated to determine the probability of being in each of the insecure attachment categories as compared to the secure style. A general multinomial logistic regression model was first utilized to examine whether any differences existed in the odds of being in one group as compared to the other three (secure was the reference to which the other three were compared). If a statistically significant difference was found, three binomial logistic regressions were calculated to determine the odds ratio, $p$-value, and effect size for each contrast to the secure group (i.e., secure vs. fearful-avoidant, secure vs. preoccupied, secure vs. dismissing-avoidant). 
Lastly, a final hiearchical model was constructed to determine the relative contribution of attachment style over and above the recovery related predictors (see Figure 3 for a visual flow chart of how variables progressed through the analyses).

Sample size. The original dataset included 128 participants. Given the variables of interest, those individuals who did not report having a home group or a sponsor were eliminated from this study. The resulting sample size was 112.

\section{Association between Nominal and Ordinal Attachment Style Ratings}

A series of one-way ANOVAS were computed to determine the relationship between participant's categorical classification and Likert-scale ratings on the four attachment styles. In other words, each categorical classification was tested to determine if the Likert-style rating that corresponded to that style was also rated the highest as compared with the three remaining styles. Significant differences in ratings amongst the Likert-scale items were observed in participants who classified as secure, $F(3,107)=$ $39.239, p<.001$; all pairwise contrasts were significant at an alpha level of less than .001. Participants who classified as secure endorsed statistically significant higher ratings on the secure Likert-scale item $(M=6.275, S D=1.041)$ as compared to the other three insecure Likert-scale items: fearful-avoidant $(M=3.000, S D=1.640, d=2.269)$, preoccupied $(M=3.667, S D=1.915, d=1.807)$, and dismissing-avoidant $(M=2.667$, $S D=1.676, d=2.500)$.

Significant differences in ratings amongst the Likert-scale items were observed in participants who classified as fearful-avoidant, $F(3,107)=27.590, p<.001$; all pairwise contrasts were significant at an alpha level of less than .001. Participants who classified 


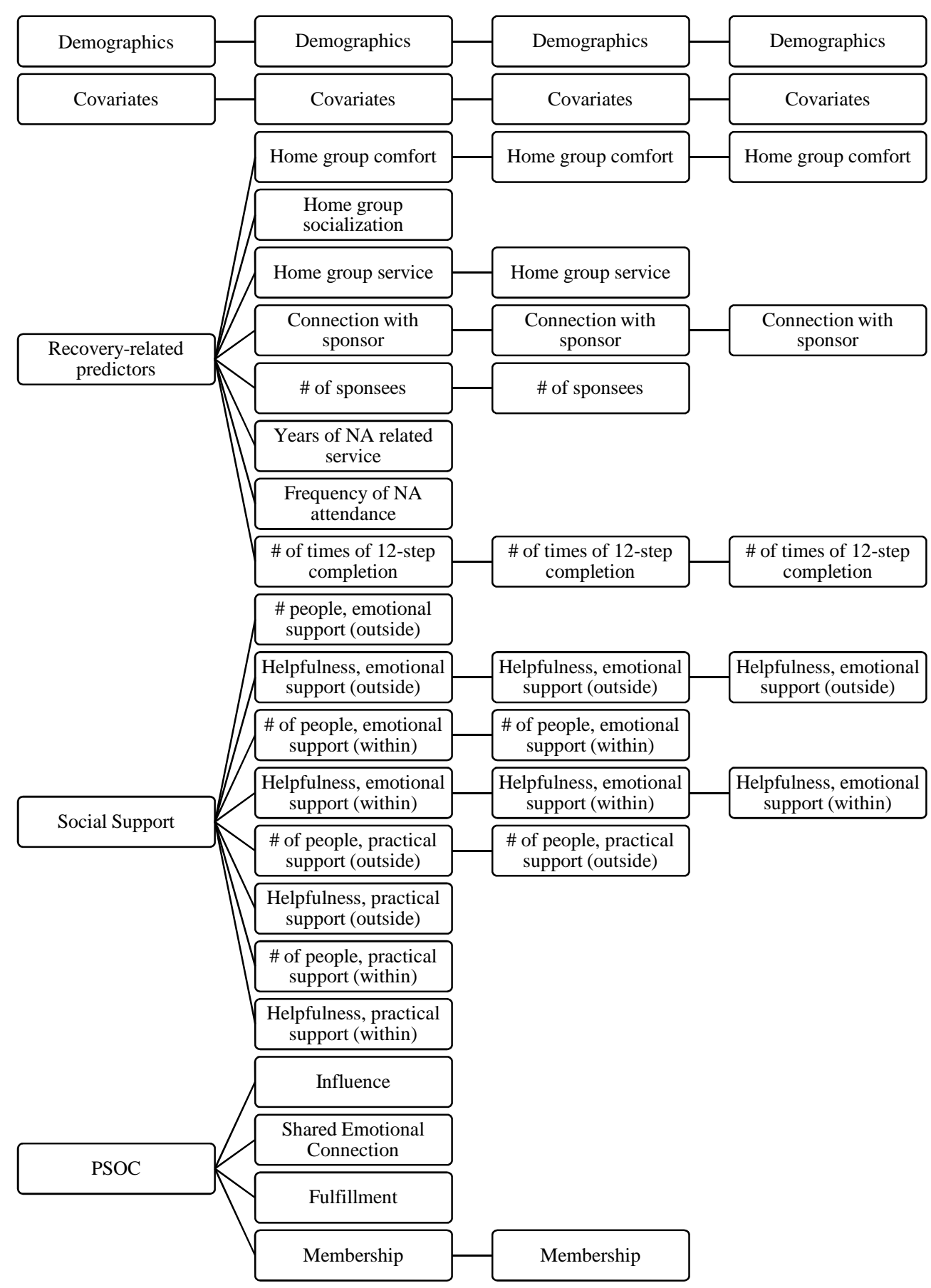

Figure 3. Flow of variables throughout analyses predicting attachment. All variables of interest were first tested with a nominal regression. If a predictor met overall significance at the .10 level, it was retained in a hierarchical model to determine its unique effect, over and above the demographic and covariate base model. Variables that persisted to the right-most column were entered into a final omnibus model. 
as fearful-avoidant endorsed statistically significant higher ratings on the fearful-avoidant Likert-scale item $(M=5.900, S D=1.062)$ as compared to the other three Likert scale items: secure $(M=2.490, S D=1.748, d=1.938)$, preoccupied $(M=3.200, S D=2.007, d$ $=1.534)$, and dismissing-avoidant $(M=3.467, S D=1.846, d=1.383)$.

Significant differences in ratings amongst the Likert-scale items were observed in participants who classified as preoccupied, $F(3,107)=14.418, p<.001$; all pairwise contrasts were significant at an alpha level of less than .001. Participants who classified as preoccupied endorsed statistically significant higher ratings on the preoccupied Likertscale item $(M=5.600, S D=1.882)$ as compared to the other three Likert-scale items: secure $(M=2.608, S D=1.511, d=1.859)$, fearful-avoidant $(M=3.067, S D=1.760, d=$ 1.573), and dismissing-avoidant $(M=2.467, S D=1.302, d=1.946)$.

Significant differences in ratings amongst the Likert-scale items were observed in participants who classified as dismissing-avoidant, $F(3,107)=13.058, p<.001$; all pairwise contrasts were significant at an alpha level of less than .001. Participants who classified as dismissing-avoidant endorsed statistically significant higher ratings on the dismissing-avoidant Likert-scale item $(M=5.867, S D=1.060)$ as compared to the other three Likert-scale items: secure $(M=2.843, S D=1.748, d=1.774)$, fearful-avoidant $(M$ $=3.433, S D=1.851, d=1.428)$, and preoccupied $(M=2.733, S D=1.751, d=1.839)$.

\section{Individual Effects of Predictors on Attachment Groups}

A series of single-predictor omnibus multinomial logit models were estimated to examine the univariate associations between the predictor variables and attachment groups. Only the three contrasts involving the secure group as the reference group were explored: a) secure vs. fearful-avoidant; b) secure vs. preoccupied; and c) secure vs. 
dissmissive-avoidant. Means and standard deviations for each of the original predictors can be found in Table 1. If the omnibus multinomal model was significant, simpler single- $d f$ logistic regression models were explored. To help describe the results for cotinuous predictors, Cohen's $d$ s are reported for pairwise contrasts when the $p$ values associated with the single- $d f$ logistic regression models were less than .10.

\section{Demographic variables as predictors of attachment styles.}

Sex. The attachment groups were not significantly differentiated by participant sex, $\chi^{2}(3)=4.911, p=.178, R_{c s}^{2}=.043$, suggesting similar percentages of men and women across the various attachment groups.

Age. Age significantly differentiated the attachment groups, $\chi^{2}(3)=9.102, p=$ $.028, R_{c s}^{2}=.078$. On average, individuals in the secure group were older than individuals in the fearful-avoidant $(d=.441)$ and preoccupied $(d=.772)$ groups.

Abstinence duration. Abstinence duration significantly differentiated the attachment groups, $\chi^{2}(3)=11.209, p=.011, R_{c s}^{2}=.095$. On average, individuals in the secure group reported longer abstinence durations than did individuals in the fearfulavoidant $(d=.537)$ and preoccupied $(d=.854)$ groups.

\section{Person-level covariates as predictors of attachment styles.}

Substance use severity. Substance use severity significantly differentiated the attachment groups, $\chi^{2}(3)=12.381, p=.006, R_{c s}^{2}=.105$. On average, individuals in the secure group reported lower degrees of substance use severity than did individuals in the fearful-avoidant $(d=-.41)$, Preoccupied $(d=-.464)$, and dismissing-avoidant $(d=-.989)$ groups. 
Table 1

Means and Standard Deviations of Recovery-Related Predictors

\begin{tabular}{|c|c|c|c|c|c|c|c|c|c|c|c|c|}
\hline \multirow[b]{2}{*}{ Predictors } & \multicolumn{3}{|c|}{ Secure } & \multicolumn{3}{|c|}{ Fearful-Avoidant } & \multicolumn{3}{|c|}{ Preoccupied } & \multicolumn{3}{|c|}{ Dismissing Avoidant } \\
\hline & $n$ & $M$ & $S D$ & $n$ & $M$ & $S D$ & $n$ & $M$ & $S D$ & $n$ & $M$ & $S D$ \\
\hline Age & 51 & 47.941 & 9.611 & 30 & 43.367 & 11.675 & 15 & 39.933 & 10.320 & 16 & 48.188 & 10.147 \\
\hline Abstinence duration & 51 & 14.453 & 8.929 & 30 & 10.301 & 6.179 & 15 & 7.858 & 5.581 & 16 & 11.621 & 7.821 \\
\hline $\begin{array}{l}\text { Substance use } \\
\text { severity }\end{array}$ & 51 & -0.298 & 0.667 & 30 & 0.032 & 0.739 & 15 & 0.073 & 0.894 & 16 & 0.492 & 1.141 \\
\hline $\begin{array}{l}\text { Unrealistic } \\
\text { Favorable } \\
\text { presentation }\end{array}$ & 51 & 3.726 & 2.384 & 30 & 2.233 & 1.775 & 15 & 3.667 & 3.244 & 16 & 3.313 & 1.778 \\
\hline Neuroticism & 51 & 2.000 & 0.721 & 30 & 3.067 & 0.907 & 15 & 2.933 & 1.223 & 16 & 2.531 & 1.161 \\
\hline $\begin{array}{l}\text { Home group } \\
\text { comfort }\end{array}$ & 51 & 3.628 & 0.780 & 30 & 2.883 & 1.165 & 15 & 3.533 & 0.667 & 16 & 2.906 & 1.172 \\
\hline $\begin{array}{l}\text { Home group } \\
\text { socialization }\end{array}$ & 51 & 3.118 & 0.925 & 30 & 2.533 & 1.238 & 15 & 3.167 & 0.976 & 16 & 2.875 & 1.057 \\
\hline $\begin{array}{l}\text { Home group } \\
\text { service }\end{array}$ & 51 & 3.412 & 0.860 & 30 & 2.822 & 1.177 & 15 & 3.333 & 0.745 & 16 & 2.604 & 1.150 \\
\hline $\begin{array}{l}\text { Connection with } \\
\text { sponsor }\end{array}$ & 50 & 4.644 & 0.327 & 30 & 4.408 & 0.510 & 15 & 4.575 & 0.642 & 16 & 4.109 & 0.376 \\
\hline $\begin{array}{l}\text { Number of } \\
\text { sponsees }\end{array}$ & 51 & 4.902 & 5.665 & 30 & 2.633 & 1.402 & 15 & 4.8 & 5.281 & 16 & 5.125 & 6.152 \\
\hline $\begin{array}{l}\text { Years of service } \\
\text { work }\end{array}$ & 51 & 5.154 & 3.937 & 30 & 3.592 & 2.971 & 15 & 3.542 & 3.798 & 16 & 3.469 & 2.889 \\
\hline $\begin{array}{l}\text { Frequency of } \\
\text { meeting } \\
\text { attendance }\end{array}$ & 51 & 6.059 & 0.835 & 30 & 5.633 & 0.964 & 15 & 6.133 & 1.246 & 16 & 5.625 & 1.025 \\
\hline
\end{tabular}




\begin{tabular}{|c|c|c|c|c|c|c|c|c|c|c|c|c|}
\hline $\begin{array}{l}\text { Number of times } \\
\text { working the 12- } \\
\text { steps }\end{array}$ & 51 & 4.020 & 3.896 & 30 & 1.700 & 1.442 & 15 & 5.133 & 7.110 & 16 & 2.688 & 3.114 \\
\hline $\begin{array}{l}\text { Number of people } \\
\text { who provide } \\
\text { emotional support } \\
\text { (outside recovery) }\end{array}$ & 50 & 3.380 & 2.813 & 30 & 2.567 & 2.813 & 15 & 3.267 & 2.219 & 16 & 2.438 & 1.999 \\
\hline $\begin{array}{l}\text { Perceived } \\
\text { helpfulness of } \\
\text { emotional support } \\
\text { (outside recovery) }\end{array}$ & 51 & 4.235 & 1.088 & 30 & 3.567 & 1.194 & 15 & 4.533 & 0.516 & 16 & 3.813 & 1.471 \\
\hline $\begin{array}{l}\text { Number of people } \\
\text { who provide } \\
\text { emotional support } \\
\text { (within recovery) }\end{array}$ & 50 & 8.040 & 6.645 & 30 & 6.833 & 6.000 & 15 & 8.467 & 8.079 & 16 & 3.938 & 3.108 \\
\hline $\begin{array}{l}\text { Perceived } \\
\text { helpfulness of } \\
\text { emotional support } \\
\text { (within recovery) }\end{array}$ & 51 & 4.902 & 0.361 & 30 & 4.500 & 0.682 & 14 & 4.571 & 0.514 & 16 & 4.188 & 1.047 \\
\hline $\begin{array}{l}\text { Number of people } \\
\text { who provide } \\
\text { practical support } \\
\text { (outside recovery) }\end{array}$ & 49 & 1.592 & 1.790 & 30 & 1.233 & 1.305 & 15 & 3.267 & 3.218 & 16 & 2.063 & 1.731 \\
\hline $\begin{array}{l}\text { Perceived } \\
\text { helpfulness of } \\
\text { practical support } \\
\text { (outside recovery) }\end{array}$ & 50 & 3.260 & 1.850 & 30 & 2.867 & 1.756 & 15 & 3.533 & 1.685 & 16 & 3.500 & 1.633 \\
\hline $\begin{array}{l}\text { Number of people } \\
\text { who provide } \\
\text { practical support } \\
\text { (within recovery) }\end{array}$ & 49 & 2.551 & 2.662 & 30 & 1.633 & 1.712 & 15 & 2.667 & 3.716 & 16 & 2.313 & 2.626 \\
\hline
\end{tabular}




\begin{tabular}{|c|c|c|c|c|c|c|c|c|c|c|c|c|}
\hline $\begin{array}{l}\text { Perceived } \\
\text { helpfulness of } \\
\text { practical support } \\
\text { (within recovery) }\end{array}$ & 50 & 3.58 & 1.617 & 30 & 3.400 & 1.714 & 15 & 3.667 & 1.799 & 16 & 2.938 & 1.692 \\
\hline PSOC Influence & 51 & 3.361 & 0.833 & 30 & 3.373 & 0.662 & 15 & 3.840 & 1.003 & 16 & 3.425 & 0.851 \\
\hline $\begin{array}{l}\text { PSOC Shared } \\
\text { Emotional } \\
\text { Connection }\end{array}$ & 51 & 4.577 & 0.483 & 30 & 4.380 & 0.488 & 15 & 4.427 & 0.483 & 16 & 4.369 & 0.529 \\
\hline PSOC Membership & 51 & 4.483 & 0.367 & 30 & 4.433 & 0.754 & 15 & 4.711 & 0.396 & 16 & 4.521 & 0.596 \\
\hline PSOC Fulfillment & 51 & 4.564 & 0.471 & 30 & 4.342 & 0.724 & 15 & 4.433 & 0.538 & 16 & 4.125 & 0.758 \\
\hline
\end{tabular}


Unrealistic favorable presentation. Unrealistic favorable presentation significantly differentiated the attachment groups, $\chi^{2}(3)=9.269, p=.026, R_{c s}^{2}=.079$. On average, individuals in the secure group reported higher levels of unrealistic favorable presentation than did individuals in the fearful-avoidant $(d=.649)$ group.

Neuroticism. Neuroticism significantly differentiated the attachment groups, $\chi^{2}$ $(3)=26.843, p<.001, R_{c s}^{2}=.213$. On average, individuals in the secure group endorsed lower levels of neuroticism than did individuals in the fearful-avoidant $(d=-1.162)$, preoccupied $(d=-1.017)$, and dismissing-avoidant $(d=-.579)$ groups.

\section{Recovery-related variables as predictors of attachment styles.}

Home group comfort. Home group comfort significantly differentiated the attachment groups, $\chi^{2}(3)=14.487, p=.002, R_{c s}^{2}=.121$. On average, individuals in the secure group reported higher levels of home group comfort than individuals in the fearful avoidant $(d=.787)$ and dismissing-avoidant $(d=.763)$ groups.

Home group socialization. The attachment groups were not significantly differentiated by home group socialization, $\chi^{2}(3)=6.588, p=.086, R_{c s}^{2}=.057$, suggesting similar levels of home group socialization across the various attachment groups.

Home group service. Home group service significantly differentiated the attachment groups, $\chi^{2}(3)=11.476, p=.009, R_{c s}^{2}=.097$. On average, individuals in the secure group reported a higher degree of home group service than individuals in the fearful-avoidant $(d=.599)$ and dismissing-avoidant $(d=.82)$ groups.

Connection with sponsor. Connection with one's sponsor significantly differentiated the attachment groups, $\chi^{2}(3)=17.009, p=.001, R_{c s}^{2}=.142$. On average, 
individuals in the secure group reported greater levels of connection with their sponsor than individuals in the fearful-avoidant $(d=.537)$ and dismissing-avoidant $(d=1.218)$ groups.

Number of sponsees. The number of sponsees significantly differentiated the attachment groups, $\chi^{2}(3)=8.287, p=.04, R_{c s}^{2}=.071$. On average, individuals in the secure group reported more sponsees than individuals in the fearful-avoidant group $(d=$ $.461)$.

Years of service. The attachment groups were not significantly differentiated by the number of years one performed service in NA, $\chi^{2}(3)=5.74, p=.125, R_{c s}^{2}=.05$, suggesting similar years of service across the attachment groups.

Frequency of past year NA meeting attendance. The attachment groups were not significantly differentiated by frequency of past-year NA meeting attendance, $\chi^{2}(3)=$ $5.978, p=.113, R_{c s}^{2}=.052$.

Number of times “working” the 12-steps. The number of times an individual completed the 12-steps significantly differentiated the attachment groups, $\chi^{2}(3)=13.193$, $p=.004, R_{c s}^{2}=.111$. On average, individuals in the secure group reported more times in which they worked the 12-steps than individuals in the fearful-avoidant $(d=.589)$ group.

\section{Social support-related variables as predictors of attachment styles.}

\section{Number of people who provide emotional support outside of the recovery}

network. The number of people who provide emotional support outside of the recovery network did not significantly differentiate the attachment groups, $\chi^{2}(3)=3.326, p=.344$, $R_{c s}^{2}=.03$. 


\section{Perceived helpfulness of emotional support from outside of the recovery}

network. Perceived helpfulness of emotional support from individuals outside of one's recovery network significantly differentiated the attachment groups, $\chi^{2}(3)=10.469, p=$ $.015, R_{c s}^{2}=.089$. On average, individuals in the secure group reported higher levels of perceived helpfulness of the emotional support received from outside of recovery than individuals in the fearful-avoidant group $(d=.594)$ group.

Number of people who provide emotional support within the recovery network. The number of people within recovery who provide emotional support significantly differentiated the attachment groups, $\chi^{2}(3)=8.459, p=.037, R_{c s}^{2}=.073$. On average, individuals in the secure group reported more friends who provided emotional support within recovery than individuals in the dismissing-avoidant group $(d=.65)$.

\section{Perceived helpfulness of emotional support from within the recovery network.}

The perceived helpfulness of emotional support from individuals within the recovery network significantly differentiated the attachment groups, $\chi^{2}(3)=20.762, p<.001, R_{c s}^{2}$ $=.171$. On average, individuals in the secure group reported higher degrees of perceived helpfulness from individuals within recovery than did individuals in the fearful-avoidant $(d=.659)$, preoccupied $(d=.542)$, and dismissing-avoidant $(d=1.17)$ groups.

\section{Number of people who provide practical support from outside of the recovery}

network. The number of people who provide practical support outside of recovery significantly differentiated the attachment groups, $\chi^{2}(3)=10.334, p=.016, R_{c s}^{2}=.09$. On average, individuals in the secure group reported fewer friends who provide practical support outside of the recovery network than did individuals in the preoccupied group ( $d$ $=-.87)$. 


\section{Perceived helpfulness of practical support from outside of the recovery network.}

The perceived helpfulness of the practical support received from individuals outside of the recovery network did not significantly differentiate the attachment groups, $\chi^{2}(3)=$ $2.12, p=.548, R_{c s}^{2}=.019$, suggesting similar ratings of the perceived helpfulness of practical support from those outside of the recovery network across the various attachment groups.

\section{Number of people who provide practical support from within the recovery}

network. The number of people who provide practical support from within the recovery network did not significantly differentiate the attachment groups, $\chi^{2}(3)=3.152, p=.369$, $R_{c s}^{2}=.028$, suggesting similar reports of the number of people within recovery who provide practical support across the various attachment groups.

\section{Perceived helpfulness of practical support from within the recovery network.}

The attachment groups were not significantly differentiated, $\chi^{2}(3)=2.055, p=.561, R_{c s}^{2}$ $=.018$, suggesting similar ratings of the perceived helpfulness of practical support from those within the recovery network across the various attachment groups.

\section{Psychological Sense of Community as a predictor of attachment styles. The} attachment groups were not significantly differentiated for three of the four PSOC scales: Influence, $\chi^{2}(3)=4.617, p=.202, R_{c s}^{2}=.04$; Shared Emotional Connection, $\chi^{2}(3)=$ 4.307, $p=.23, R_{c s}^{2}=.038$; and Fulfillment, $\chi^{2}(3)=6.957, p=.073, R_{c s}^{2}=.06$. However, the Membership scale significantly differentiated the attachment groups, $\chi^{2}(3)=11.713$, $p=.008, R_{c s}^{2}=.099$. On average, secure individuals reported higher levels of Membership than individuals in the fearful-avoidant group $(d=.093)$, and lower levels of Membership than individuals in the dismissing-avoidant group $(d=.071)$. 


\section{Relative Contribution of Predictors to a Base Model on Attachment Groups}

In the next stage of analyses, predictors other than the core demographic variables (sex, age, and abstinence duration) and covariates (substance use severity, unrealistic favorable presentation, and neuroticism) were eliminated from further consideration if they failed to significantly differentiate the attachment groups in the single-predictor models reported above. Based on the above findings, the following recovery-related variables were excluded at this stage of analysis: home group socialization, number of years of NA-related service, and frequency of attendance at NA meetings in the past year. The following social support-related variables were excluded: number of people outside of the recovery network who provide emotional support, perceived helpfulness of practical support received from those outside of the recovery network, number of people who provide practical support within the recovery network, and the perceived helpfulness of practical support received from those within recovery. Lastly, the following PSOC subscales were excluded: Influence, Shared Emotional Connection, and Fulfillment.

For all variables that were significant above, several hierarchical models were run to determine the relative contribution of each of the primary attachment predictors to a common "base" model that included the demographics (sex, age, abstinence duration) and covariates (substance use severity, unrealistic favorable presentation, and neuroticism). To form the common "base" model, the demographic predictors and covariates were entered first — accounting for significant differences in attachment styles, $\chi^{2}(18)=56.747, p<.001, R_{c s}^{2}=.397$. Next, the following 11 predictor variables of interest were then entered into the hierarchical model; change statistics for the chi-square test and the associated change in approximated $R^{2}$ values are reported. If the $p$ value 
associated with the change in chi-square was less than .05 , the predictor was deemed statistically significant—suggesting a unique contribution to the model, above demographics and covariates.

Home group comfort. Home group comfort accounted for further differences, above demographics and covariates, among the attachment styles, $\Delta \chi^{2}(3)=11.032, p=$ $.01, \Delta R_{c s}^{2}=.057$.

Home group service. Home group service did not account for further differences, above demographics and covariates, among the attachment styles, $\Delta \chi^{2}(3)=7.573, p=$ $.056, \Delta R_{c s}^{2}=.04$.

Connection with sponsor. Connection with one's sponsor accounted for further differences, above demographics and covariates, among the attachment styles, $\Delta \chi^{2}(3)=$ $11.495, p=.009, \Delta R_{c s}^{2}=.062$.

Number of sponsees. The number of sponsees did not account for further differences, above demographics and covariates, among the attachment styles, $\Delta \chi^{2}(3)=$ 7.728, $p=.051, \Delta R_{c s}^{2}=.041$.

Number of times "working" the 12-steps. The number of times of 12-step completion accounted for further differences, above demographics and covariates, among the attachment styles, $\Delta \chi^{2}(3)=9.841, p=.02, \Delta R_{c s}^{2}=.051$.

\section{Perceived helpfulness of emotional support from outside of the recovery}

network. Perceived helpfulness of emotional support from outside of one's recovery network accounted for further differences, above demographics and covariates, among the attachment styles, $\Delta \chi^{2}(3)=13.329, p=.004, \Delta R_{c s}^{2}=.068$. 


\section{Number of people who provide emotional support within the recovery}

network. The number of people within recovery who provide emotional support did not account for further differences, above demographics and covariates, among the attachment styles, $\Delta \chi^{2}(3)=6.366, p=.095, \Delta R_{c s}^{2}=.037$.

\section{Perceived helpfulness of emotional support from within the recovery}

network. The perceived helpfulness of emotional support from individuals within the recovery network accounted for further differences, above demographics and covariates, among the attachment styles, $\Delta \chi^{2}(3)=15.71, p=.001, \Delta R_{c s}^{2}=.082$.

\section{Number of people who provide practical support from outside of the} recovery network. The number of people who provide practical support outside of recovery did not account for further differences, above demographics and covariates, among the attachment styles, $\Delta \chi^{2}(3)=7.669, p=.053, \Delta R_{c s}^{2}=.046$.

Membership scale of PSOC. The Membership subscale of PSOC did not account for further differences, above demographics and covariates, among the attachment styles, $\Delta \chi^{2}(3)=5.609, p=.167, \Delta R_{c s}^{2}=.03$.

Overall analysis of remaining predictors. Predictors that did not offer a statistically significant contribution to the base model of demographics and covariates were omitted from this final analysis. The following variables were excluded based on the preceding analyses: home group socialization, home group service, number of sponsees, number of people who provide emotional support within the recovery network, and number of people who provide practical support outside of the recovery network.

The remaining predictors were then entered in one final omnibus block of predictors: demographics (sex, age, abstinence duration), covariates (substance use 
severity, unrealistic favorable presentation, neuroticism), home group comfort, connection with one's sponsor, number of times of 12-step completion, and helpfulness of emotional support both within and outside of the recovery network. The omnibus block of predictors accounted for further differences, above demographics and covariates, among the attachment styles, $\Delta \chi^{2}(15)=61.329, p<.001, \Delta R_{c s}^{2}=.261$.

\section{Odds Ratios for Categorization in the Secure Attachment Style}

Additional hierarchical models were run to determine the unique effect of each of the primary predictor variables on the odds of being categorized in each of the three insecure styles compared to the secure style (yielding three models of secure and fearfulavoidant, secure and preoccupied, and secure and dismissing-avoidant). Odds ratios for the three contrasts can be located in Table 2 .

Secure and fearful-avoidant. The full model accounted for significant differences, $\chi^{2}(11)=64.997, p<.001, R_{c s}^{2}=.556$. The unique effect for home group comfort was significant in differentiating fearful-avoidant and secure styles, $\Delta \chi^{2}(1)=$ $4.26, p=.039, \Delta R_{c s}^{2}=.024$. Higher levels of home group comfort were associated with a higher likelihood of being in the securely attached group $(O R=2.611)$. The unique effect for connection with one's sponsor was significant in differentiating fearful-avoidant and secure styles, $\Delta \chi^{2}(1)=5.26, p=.022, \Delta R_{c s}^{2}=.034$. Higher levels of connection with one's sponsor were associated with a higher likelihood of being in the securely attached group $(O R=2.273)$. The unique effect for the number of times one has worked the 12 steps was significant in differentiating fearful-avoidant and secure styles, $\Delta \chi^{2}(1)=5.83, p=.012, \Delta R_{c s}^{2}=.033$. More times working the 12-steps were associated with a higher likelihood of being in the securely attached group $(\mathrm{OR}=1.676)$. 
Table 2

Odds Ratios for Categorization in the Secure Attachment Style

\begin{tabular}{|c|c|c|c|}
\hline Predictors & $\begin{array}{l}\text { Secure vs. } \\
\text { Fearful- } \\
\text { Avoidant }\end{array}$ & $\begin{array}{l}\text { Secure vs. } \\
\text { Preoccupied }\end{array}$ & $\begin{array}{l}\text { Secure vs. } \\
\text { Dismissing - } \\
\text { Avoidant }\end{array}$ \\
\hline \multicolumn{4}{|l|}{ Demographics } \\
\hline Sex & $7.99 *$ & $72.146^{*}$ & $275.226 *$ \\
\hline Age & 1.041 & 1.054 & $1.379 *$ \\
\hline Abstinence duration & 1.023 & 1.152 & 1.127 \\
\hline \multicolumn{4}{|l|}{ Person-level Covariates } \\
\hline Substance use severity & 2.725 & 3.451 & 3.106 \\
\hline Unrealistic favorable presentation & 1.394 & 1.325 & 3.936 \\
\hline Neuroticism & $14.493 *$ & $5.208 *$ & $10.309 *$ \\
\hline \multicolumn{4}{|l|}{ Recovery-Related predictors } \\
\hline Home group comfort & $2.611 *$ & 1.436 & $15.713 *$ \\
\hline Connection with one's sponsor & $2.273^{*}$ & $175.63 *$ & $489.956^{*}$ \\
\hline $\begin{array}{l}\text { Number of times working the 12- } \\
\text { steps }\end{array}$ & $1.676^{*}$ & 1.189 & 1.33 \\
\hline $\begin{array}{l}\text { Perceived helpfulness of emotional } \\
\text { support (within recovery) }\end{array}$ & $33.558^{*}$ & $150166.32 *$ & $291.416^{*}$ \\
\hline $\begin{array}{l}\text { Perceived helpfulness of emotional } \\
\text { support (outside recovery) }\end{array}$ & 1.861 & $26.06^{*}$ & 2.169 \\
\hline
\end{tabular}

The unique effect for the perceived helpfulness of emotional support from within the recovery network was significant in differentiating fearful-avoidant and secure styles, $\Delta \chi^{2}(1)=7.2, p=.007, \Delta R_{c s}^{2}=.042$. Higher levels of perceived helpfulness of emotional support from within the recovery network was associated with a higher likelihood of being in the securely attached group $(\mathrm{OR}=33.558)$. However, the unique effect for the perceived helpfulness of emotional support from outside of the recovery network was not 
significant in predicting one's classification as fearful-avoidant or secure, $\Delta \chi^{2}(1)=2.61$, $p=.106, \Delta R_{c s}^{2}=.014$.

Secure and preoccupied. The full model accounted for significant differences, $\chi^{2}(11)=42.197, p<.001, R_{c s}^{2}=.483$. The unique effect for connection with one's sponsor was significant in differentiating preoccupied and secure styles, $\Delta \chi^{2}(1)=15.5, p$ $<.001, \Delta R_{c s}^{2}=.0146$. Higher levels of connection with one's sponsor were associated with a higher likelihood of being in the securely attached group ( $O R=175.63)$. The unique effect for the perceived helpfulness of emotional support from within the recovery network was significant, $\Delta \chi^{2}(1)=19.9, p<.001, \Delta R_{c s}^{2}=.192$. Higher levels of perceived helpfulness of emotional support from within the recovery network were associated with a higher likelihood of being in the securely attached group $(\mathrm{OR}=150166.316)$. The unique effect for the perceived helpfulness of emotional support from outside of the recovery network was also significant, $\Delta \chi^{2}(1)=9.54, p=.002, \Delta R_{c s}^{2}=.083$. Higher levels of perceived helpfulness of emotional support from outside of the recovery network were associated with a higher likelihood of being in the securely attached group $(\mathrm{OR}=26.06)$. The unique effect for home group comfort was not significant in differentiating preoccupied and secure styles, $\Delta \chi^{2}(1)=.09, p=.764, \Delta R_{c s}^{2}=.001$, nor was the unique effect for the number of times one has worked the 12-steps significant in differentiating preoccupied and secure styles, $\Delta \chi^{2}(1)=1.21, p=.271, \Delta R_{c s}^{2}=.01$.

Secure and dismissing-avoidant. The full model accounted for significant differences, $\chi^{2}(11)=55.447, p<.001, R_{c s}^{2}=.568$. The unique effect for home group comfort was significant in differentiating dismissing-avoidant and secure styles, $\Delta \chi^{2}(1)=$ $9.09, p=.003, \Delta R_{c s}^{2}=.063$. Higher levels of home group comfort were associated with a 
higher likelihood of being in the securely attached group $(\mathrm{OR}=15.713)$. The unique effect for connection with one's sponsor was significant in differentiating dismissingavoidant and secure styles, $\Delta \chi^{2}(1)=16.8, p<.001, \Delta R_{c s}^{2}=.0129$. Higher levels of connection with one's sponsor were associated with a higher likelihood of being in the securely attached group $(\mathrm{OR}=489.956)$. The unique effect for the perceived helpfulness

of emotional support from within the recovery network was significant, $\Delta \chi^{2}(1)=14.2, p$ $<.001, \Delta R_{c s}^{2}=.103$. Higher levels of perceived helpfulness of emotional support from within the recovery network were associated with a higher likelihood of being in the securely attached group $(\mathrm{OR}=291.416)$. The unique effect for the number of times one has worked the 12-steps was not significant in differentiating dismissing-avoidant and secure styles, $\Delta \chi^{2}(1)=.64, p=.424, \Delta R_{c s}^{2}=.004$. Additionally, the unique effect for the perceived helpfulness of emotional support from outside of the recovery network was not significant, $\Delta \chi^{2}(1)=1.55, p=.213, \Delta R_{c s}^{2}=.01$.

\section{Attachment Style as a Predictor of Psychological Well-Being}

In the final set of analyses, attachment groups were entered as a final block to a hierarchical model with demographics, covariates, and the recovery-related predictors also entered as separate blocks. The purpose of these final analyses was to determine if attachment predicted psychological well-being over and above the other predictors in the model. Six models were created for each of Ryff's (1995) psychological well-being subscales: self-acceptance, autonomy, environmental mastery, personal growth, purpose in life, and positive relations with others.

The main effect for attachment style was significant in predicting self-acceptance, $F(3,108)=6.596, p<.001, R^{2}=.155$. However, when the other predictors were entered 
into the model, neither the recovery-related predictors $\left(R^{2} \Delta=.035, p=.274\right)$ nor attachment style $\left(R^{2} \Delta=.017, p<.387\right)$ added significant variance to the model in predicting self-acceptance. As such, attachment style predicted self-acceptance, but failed to predict it over and above the additional recovery-related variables in the larger model.

The main effect for attachment style was significant in predicting autonomy, $F(3$, $108)=5.507, p<.001$. However, when the other predictors were entered into the model, neither the recovery-related predictors $\left(R^{2} \Delta=.033, p=.477\right)$ nor attachment style $\left(R^{2} \Delta=\right.$ $.020, p<.444)$ added significant variance to the model in predicting autonomy. As such, attachment style predicted autonomy, but failed to predict it over and above the additional recovery-related variables in the larger model.

The main effect for attachment style was significant in predicting environmental mastery, $F(3,108)=7.605, p<.001$. However, when the other predictors were entered into the model, neither the recovery-related predictors $\left(R^{2} \Delta=.032, p=.165\right)$ nor attachment style $\left(R^{2} \Delta=.024, p<.111\right)$ added significant variance to the model in predicting environmental mastery. As such, attachment style predicted environmental mastery, but failed to predict it over and above the additional recovery-related variables in the larger model.

The main effect for attachment style was significant in predicting personal growth, $F(3,108)=5.750, p=.001$. The recovery-related predictors $\left(R^{2} \Delta=.166, p<\right.$ .001) added significant incremental variance over and above the demographics and covariates. However, when the other predictors were entered into the model, attachment style $\left(R^{2} \Delta=.013, p<.538\right)$ did not add significant incremental variance to the model in predicting personal growth. As such, attachment style predicted personal growth, but 
failed to predict it over and above the additional recovery-related variables in the larger model.

The main effect for attachment style was significant in predicting purpose in life, $F(3,108)=6.249, p=.001$. The recovery-related predictors $\left(R^{2} \Delta=.104, p=.011\right)$ added significant incremental variance over and above the demographics and covariates. However, when the other predictors were entered into the model, attachment style $\left(R^{2} \Delta=\right.$ $.014, p<.548)$ did not add significant incremental variance to the model in predicting purpose in life. As such, attachment style predicted purpose in life, but failed to predict it over and above the additional recovery-related variables in the larger model.

The main effect for attachment style was significant in predicting positive relations with others, $F(3,108)=14.578, p<.001$. The recovery-related predictors $\left(R^{2} \Delta\right.$ $=.163, p<.001)$ added significant incremental variance over and above the demographics and covariates. However, when the other predictors were entered into the model, attachment style $\left(R^{2} \Delta=.020, p<.270\right)$ did not add significant incremental variance to the model in predicting positive relations with others. As such, attachment style predicted positive relations with others, but failed to predict it over and above the additional recovery-related variables in the larger model. 


\section{Discussion}

\section{Multidimensional Nature of Attachment}

As expected, participants who rated themselves as secure, also rated themselves highly on the scale for a secure attachment style and rated themselves lower for the remaining three insecure styles. This pattern was also observed for the insecure styles in which the category chosen corresponded to a higher rating on the Likert-scale item (i.e., those individuals who classified themselves as preoccupied also rated themselves highly on the preoccupied Likert-scale item, and rated themselves lower on the other three styles' Likert-scale items, and so on). This finding suggests a fairly consistent overlap of participants' self-selection into a particular attachment category and their ratings on the items designed to capture the multidimensional nature of attachment.

\section{Predictors of Attachment}

Demographics. There were no observed differences amongst the groups in regards to sex, suggesting that there was no gender effect for a particular attachment classification. Older individuals, on average, tended to select into the secure group, as compared to the fearful-avoidant and preoccupied styles.

Abstinence duration. Those individuals who rated themselves as having a secure attachment style had, on average, longer periods of abstinence, followed by dismissingavoidant, fearful-avoidant, and preoccupied styles (in that order). The secure group was significantly different from the fearful-avoidant and preoccupied attachment classifications (but not from dismissing-avoidant style). This was contrary to original hypotheses that a fearful-avoidant style would be associated with the shortest periods of abstinence duration as compared to the other three styles. While longer periods of 
abstinence may help to differentiate secure from insecure, it does not seem to meaningfully differentiate among the insecure styles. Abstinence duration, or time in recovery, may not play as prominent a role in the recovery process as some of the other more social and attachment-related predictors. Secure individuals endorsed the longest abstinence duration periods, suggesting that over time (e.g., recovery) a secure attachment may be forged. This may point to attachment style changing as an effect of involvement in NA and the 12-steps program.

Substance use severity. Secure individuals reported lower degrees of substance use severity compared to the three insecure styles. Substance use severity may be diminished in individuals who have a secure attachment at the time of their drug addiction because they have a greater capacity to both seek out and utilize resources.

Neuroticism. Secure individuals endorsed lower levels of neuroticism as compared to the three insecure styles. Individuals who are securely attached, by nature, are comfortable with their core model of self and other, which may contribute to their endorsement of lower levels of negative emotional reactivity. It is important to note that the neuroticism scale taps into two concepts - one's ability to handle stress and one's awareness of nervousness that they experience. Individuals in the secure attachment style who were secure pre-addiction as well as those individuals who may have become secure as a result of the 12-step intervention, may be more likely to handle stress well and have substantial insight into their nervousness since these tenets are core to the 12 -steps (e.g., "We made a searching and fearless moral inventory of ourselves," "We admitted to G-d, to ourselves, and to another human being the exact nature of our wrongs" (Narcotics Anonymous World Services, 1986). 
Unrealistic favorable presentation. Providing an unrealistic favorable presentation predicted attachment differentiation between the secure and fearful-avoidant groups. Fearful-avoidant individuals endorse a sense of unworthiness as well as an expectation of others as rejecting, and so they may be more likely to admit faults (leading to lower scores on the MMPI-L Scale). More remarkable is that securely attached individuals reported higher scores on the scale. Such an unrealistic favorable presentation may not in fact be unrealistic, as research has shown that increases in secure attachment lead to altruistic behaviors and more compassion (Mikulincer, Shaver, Gillath, Nitzberg, 2005). This may then translate into securely attached individuals acting in ways that are more socially approving ways given their time in recovery.

Home group and social-support. Comfort at one's home group significantly differentiated the attachment groups, indicating that insecure styles endorsed lower degrees of home group comfort. The secure and preoccupied styles did not have statistically significant differences; the commonality of having a positive model of others may make these two styles more alike than the other two insecure styles (dismissingavoidant and fearful-avoidant) that have a negative model of others. Home group comfort continued to be a strong predictor of secure attachment throughout all analyses.

Home group socialization was not a significant predictor of attachment differentiation. The perceived helpfulness of practical support (both within and outside of the recovery network) was also not significant in predicting attachment differentiation. The feeling of being supported emotionally seems to play a more prominent role in secure attachment as compared to more practical forms of social support and 
socialization. Although home group service differentiated attachment styles, it did not predict attachment style above and beyond the base model.

Perceived helpfulness of emotional support within the recovery network was the most robust social-support predictor of attachment suggesting that it is not what others do to support one another, but how others support one another that is influential. In a study of 100 individuals recovering from an alcohol use disorder, participants generally rated their affiliative feelings for 12-step members higher than for non-members (Galanter et al., 1990), demonstrating the shared emotional connection implicit in 12-step membership. Further, the home group may in fact act as a secure base and transitional object for members. The fellowship aspect of NA may help to repair any attachment disruptions and thus form a more secure attachment for the individual. The simple act of asking for help is already a marked change in attachment as it begins to change the negative models of self and others.

The number of people who provide support, emotional or practical and within or outside of the recovery network, was not associated with differentiation of the attachment styles over and above the demographic and covariate variables. Additionally, the number of years of NA-related service and the frequency of past year NA meeting attendance yielded no attachment differentiation. In sum, it appears that frequency counts of attendance or the number of people within a network does not predict differentiation in attachment style. This lends support to the importance of functional support - the meaningfulness and usefulness of support provided by members within the recovery network - while deemphasizing the importance of structural support or the composition of one's network (Groh, Jason, \& Keys, 2007). 
Sponsor-sponsee relationship. Connection with one's sponsor was a strong predictor of attachment differentiation. Members are encouraged to seek out sponsors soon after joining NA. Shorter periods of abstinence were associated with more insecure styles, suggesting that when members first join the group they may not have a secure attachment. Sponsors are members who likely have longer periods of abstinence duration and a longer involvement with NA than newer members. The forged relationship between sponsor and sponsee may result in a transmission of interpersonal skills and empathic validation from the more securely attached sponsor to the more insecurely-attached sponsee. This relationship is conceptualized as bidirectional in nature; as the sponsor guides the sponsee, he or she also makes tremendous gains in mental health (Schwartz, Meisenhelder, Ma, \& Reed, 2003; Zemore \& Pagano, 2008).

Psychological sense of community (PSOC). It was hypothesized that the four subscales of PSOC would predict attachment style differentiation, with higher levels of PSOC being associated with secure attachment. The Influence, Fulfillment of Needs, and Shared Emotional Connection subscales were all nonsignificant in models predicting differentiation of secure and insecure attachment styles. While the Membership scale was associated with differentiation, it did not account for differences over and above the base model of demographics and covariates.

The secure group reported statistically significant higher levels of Membership than those individuals in the fearful-avoidant group. As diametric styles, this suggests that a negative model of self and of others (i.e., poor feelings of self-worth and a mistrust of others) impacts one's subjective feelings of belonging and membership. 
Final model of predictors of attachment style. Ultimately, there were five variables that were retained for the final model in predicting attachment style: home group comfort, connection with one's sponsor, number of times of 12-step completion, and helpfulness of emotional support within and outside of the recovery network. The commonality amongst these predictors is their focus on emotional support and relatedness, indicating that endorsement of higher levels of connection differentiates the attachment styles and can predict secure attachment. Twelve-step groups allow for members to influence other members, the home group, and the organization as a whole through service roles (e.g., working the coffee bar, or participating in an administrative context) and as sponsors. Conversely, 12-step organizations exert influence through such means as the 12 Steps and organization literature (e.g., the Basic Text in NA or Big Book in AA), which act as guiding principles for its members. NA fosters the reciprocal relationship and connectedness by encouraging members to be empathic and validating of one another, creating a mutual emotionally fulfilling network of relationships.

\section{Differentiating the Four Styles of Attachment}

Connection with one's sponsor and perceived helpfulness of emotional support from within the recovery network provided unique effects for differentiating the secure and insecure styles. Reporting a stronger connection with one's sponsor and reporting higher levels of perceived emotional support contributed to an increased likelihood that individuals would be in the securely attached group. Emotional support from outside of the recovery network only served to differentiate the secure and preoccupied styles. This highlights the unique effect that subjective experiences of connection within the 12-step group seem to be the most robust predictors of secure attachment. Connections outside of 
the NA group appear to be de-emphasized for individuals, suggesting that there is a relationship between in-recovery relationships and secure attachment.

Home group comfort did not increase the likelihood of being in the secure group, as compared to the preoccupied group. Secure and preoccupied are similar in that they both maintain a positive model of others with a general expectation that others can provide emotional support. As such, there may be fewer differences between these two attachment classifications in the level of home group comfort endorsed.

The number of times "working" the 12-steps did not increase the likelihood of being in the secure group, as compared to the preoccupied and dismissing-avoidant groups. It was, however, associated with a higher likelihood of being in the securely attached group as compared to the fearful-avoidant group. The 12-steps foster important inter- and intra-personal gains; over time, and with multiple times of completion, the 12steps likely contribute to a secure style. Since the dismissing-avoidant style comprises both negative models of self and others, this group may stand apart from the other styles. Having at least one positive model (of self or other) seems to mitigate any differences between secure and the preoccupied and dismissing-avoidant styles.

Reporting a secure attachment style was associated with greater degrees of home group comfort, connection with one's sponsor, and perceived helpfulness of members within the recovery network. Caspers and colleagues (2006) found that the odds of an abuse or dependency diagnosis increased three times for insecure attachment styles. Temporal conclusions are limited, but it can be hypothesized that individuals who enter into substance abuse treatment have greater degrees of insecure attachment than secure. Mutual self-help groups, in particular NA, may supply the necessary relational support to 
transform one's model of others and the program support to transform one's model of self. Membership in the NA group at large is not a robust predictor of secure attachment, suggesting that smaller and more personal factors (e.g., the one-on-one sponsor connection and home group comfort) are primary mechanisms of action.

\section{Attachment and Recovery-Related Variables as Predictors of Psychological Well-}

\section{Being}

The recovery-related variables only added significant incremental variance to the overall model in predicting psychological well-being for personal growth, purpose in life, and positive relations with others. However, the predictors did not add variance over and above the demographics and covariates for autonomy, environmental mastery, and selfacceptance.

Secure attachment predicted all aspects of psychological well-being suggesting that changes in attachment, from insecure to secure, may be beneficial in the recovery process. As discussed above, the 12-steps foster several changes. For one, the 12-steps and the associated program content encourage intrapersonal changes that can be reflected in personal growth. Furthermore, by nature of it being a mutual self-help group, interpersonal changes also occur that can be reflected in positive relations with others. The 12-step program encourages forgiveness of past transgressions that in turn leads to the creation of a present-focused purpose in life. Narcotics Anonymous, and other 12-step help groups, embrace the idea of mutual and reciprocal support giving. From an attachment theory perspective, by supporting one another, these individuals are instilled with a sense of autonomy to wander from the secure base, but with an ability to return for reassurance and comfort. Attachment style also predicted environmental mastery, a 
feeling of fitting in to the community at large. Membership in PSOC, similar to this subscale, also suggested some interesting findings—namely, secure individuals reported higher levels of Membership than individuals in the fearful-avoidant group and lower levels of Membership than individuals in the dismissing-avoidant group. Feelings of belonging to the group, or feelings of belonging in the community seem to play as important of a role in predicting attachment style. It appears that micro-level interactions (e.g., relationships with other members, relationship with one's sponsor) and macro-level (e.g., fitting in with the group at large) both play prominent roles in recovery. Lastly, selfacceptance was also predicted, likely because of NA's encouragement of radical acceptance and a positive outlook towards the future. Attachment style did not mediate the relationship between recovery-related predictors and psychological well-being as an outcome. This may be due to the fact that the recovery-related predictors already offer a multidimenionsal understanding of secure attachment (e.g., home group comfort, attachment with one's sponsor, social support) and the attachment construct is not diverse enough of a construct to add additional variance to the models.

\section{Limitations}

There are several limitations of the current study. Most importantly, as with any cross-sectional study, data is gathered at only one time point reducing clarity in regards to temporal precedence and causal interpretations. As such, it is still unclear as to whether attachment style is directly affected by 12 -step membership.

There are several limitations with the Relationship Questionnaire (Bartholomew \& Horowitz, 1991), which was utilized to measure attachment style in the current study. Among researchers in the field of attachment, there is a general consensus that a 
continuous scale of attachment carries greater measurement benefits than a categorical classification. The multidimensional nature of attachment means that individuals rarely fall into one mutually exclusive category, but rather may identify strongly with one category, and also endorse various traits of the other styles. In the current study, this was addressed by examining the multidimensional profile. For each style that an individual selects as their preferential style, they were also shown to have higher endorsements of that style for the continuous scale. This suggested that using the categorical classification system was a crude, albeit effective, means of measuring one's overarching attachment style.

Since the advent of the RQ (Bartholomew \& Horowitz, 1991), more advanced measurement tools that incorporate multiple items — as opposed to the eight items in the RQ - have been utilized in attachment studies. The Experiences in Close RelationshipsRevised (ECR-R; Fraley, Waller, \& Brennan, 2000) includes 36 items that resulted from an item response theory analysis of existing self-report measures of adult romantic attachment. Like the RQ, it measures Avoidance (Model of Other) and Anxiety (Model of Self). Using a more psychometrically sound instrument, as well as multiple items, would greatly enhance construct validity.

\section{Conclusions, Strengths, and Future Directions}

Conclusions. The role of attachment in substance use development and 12-step treatment is one that has gained significantly more theoretical attention in the past years, but not enough empirical focus. Additionally, there has been a call for substance use research to explore the various mechanisms of action by which 12-step interventions foster recovery. This study investigated the impact of 12-step recovery-related constructs 
(e.g., social support, fellowship, 12-step tenets) in predicting secure attachment in a sample of NA members. Several factors emerged as primary predictors of secure attachment: home group comfort, connection with one's sponsor, perceived helpfulness of emotional support received from members within recovery as well as individuals outside of the recovery network, and number of times the 12-steps were "worked." These findings support the notion that such peer-based support can offer prediction of secure attachment over and above other recovery-related variables such as service to one's home group, frequency of attendance at NA meetings, receiving practical support, and number of friendships. Lastly, the study also indicated that feeling a sense of belonging as part of a psychological sense of community predicted some differentiation among the four attachment styles, but not over and above person-level covariates. Comfort and connection appear to be primary factors in the differentiation of the attachment styles, rather than a sense of membership and inclusion.

Strengths. The current study had several notable strengths. For one, empirical investigation of the role of attachment in SUDs is limited in the sheer number of studies that have been carried out, as well as by populations that have been utilized. A major strength of this study is that it can add to the current scope of research by generalizing to less studied populations such as Narcotics Anonymous. Another strength is its contribution to gaps in the field - such as understanding recovery-related predictors of attachment, something that has not been directly studied before. The inclusion of more specific recovery-related practices, social support items, and measures of psychological sense of community and psychological well-being are yet another direct strength of this study. Understanding the role of social support recovery-related predictors can potentially 
impact not only NA, and other mutual self-help organizations, but also interventions outside of the 12-step domain. It appears that some of the most significant pieces of NArecovery are one's home group, sponsor, general emotional support, and the 12-steps. Though these facets are widely endorsed by 12-step groups and members are encouraged to find home groups and sponsors, it is worth noting why these program aspects are beneficial to recovery and abstinence.

Future directions. It is hoped that the current study can serve as an impetus for future studies to examine the role of attachment in both the development and treatment of SUDs, due to the relatively small number of available studies. Studying these attachment patterns may help providers to identify risk factors for substance use, allowing for the employment of earlier interventions. Future studies could benefit from a pre- to postintervention design in which attachment style is measured at baseline and at various points of membership, allowing for the assessment of how 12-step groups may foster these changes. This would lead to a better understanding of the particular mechanisms of action that occur within these groups; if social support and community fellowship are determined to be causal factors of recovery and longer periods of abstinence duration, then these constructs can be generalized to additional treatment interventions.

Future studies may wish to examine the role of PSOC as it relates to the home group. Findings from this study illustrate that feeling one is able to influence others, share an emotional connection, and fulfill their needs of belonging do not apply to Narcotics Anonymous as an organization. However, other recovery-related predictors that were examined captured these themes. As such, a sense of community may be present but only on an individual group level and this notion should be explored further. 


\section{References}

Alcoholics Anonymous World Services (2005). The A.A. group...Where it all begins. [Pamphlet]. New York: A.A. Grapevine, Inc.

Ainsworth, M., Blehar, M., Waters, E., \& Wall, S. (1978). Patterns of Attachment. Hillsdale, NJ: Erlbaum.

Allen, J. P., Hauser, S. T., Borman-Spurell, E. (1996 ). Attachment theory as a framework for understanding sequelae of severe adolescent psychopathology: An 11-year follow-up study. Journal of Consulting and Clinical Psychology, 64(2), 254-263.

Bartholomew, K., \& Horowitz, L. M. (1991). Attachment styles among young adults: A test of a four-category model. Journal of Personality and Social Psychology, 61(2), 226-244.

Bogenschultz, M., Tonigan, J. S., \& Miller, W. R. (2006). Examining the effects of alcoholism typology and AA attendance on self-efficacy as a mechanism of change. Journal of Studies on Alcohol, 67(4), 562-567.

Bowlby, J. (1969). Attachment and loss, Vol. 1: Attachment. New York: Basic Books.

Bretherton, I. (1992). The origins of attachment theory: John Bowlby and Mary Ainsworth. Developmental Psychology, 28(5), 759-775.

Calabrese, R. L., \& Schumer, H. (1986). The effects of service activities on adolescent alienation. Adolescence, XXI(8), 675-687.

Caspers, K. M., Yucuis, R., Troutman, B., \& Spinks, R. (2006). Attachment as an 
organizer of behavior: Implications for substance abuse problems and willingness to seek treatment. Substance Abuse Treatment, Prevention, and Policy, 1(32). doi: 10.1186/1747-597X-I-32.

Chassin, L., Pitts, S. C., DeLucia, C., \& Todd, M. (1999). A longitudinal study of children of alcoholics: Predicting young adult substance use disorders, anxiety and depression. Journal of Abnormal Psychology, 108, 106-119.

Chassin, L., Ritter, J., Trim, R. S., \& King, K. M. (2003). Adolescent substance use disorders. In E. J. Mash \& R. A. Barkley (Eds.), Child psychopathology (199230). New York: The Guilford Press.

Cicchetti, D. (1993). Developmental psychopathology: Reactions, reflections, projections. Developmental Review, 13, 471-502.

Compton, W. M., Thomas, Y. E, Stinson, E S., \& Grant, B. E. (2007). Prevalence, correlates, disability, and comorbidity of DSM-IV drug abuse and dependence in the United States: Results from the National Epidemiologic Survey on Alcohol and Related Conditions. Archives of General Psychiatry, 64(5), 566-576.

Cross, G. M., Morgan, C. W., Mooney, A. J., Martin, C. A., \& Rafter, J. A. (1990). Alcoholism treatment: A ten-year follow-up study. Alcoholism: Clinical and Experimental Research, 14(2), 169-173.

DeLucia, C., Bergman, B. G., Bruder, L. M., \& Formoso, D. (2010). Recovery in Narcotics Anonymous from the perspectives of long-term members. Unpublished manuscript, Nova Southeastern University.

DeLucia, C., Bergman, B., Heinowitz, A., Beitra, D., Seibert, S., Howrey, H., \& 
Mizrachi, J. (2012). Recovery-related predictors of psychological well-being among Narcotics Anonymous members [Abstract]. Research Society on Alcoholism. Retrieved from: http://onlinelibrary.wiley.com/store/10.1111/j.15300277.2012.01803.x/asset/j.1530-

0277.2012.01803.x.pdf?v=1\&t=h3p3krsy\&s=72e80c2eb18dafc1864151b977a573 c5b4f3245e

Fairbairn, W. R. D. (1958). On the nature and aims of psychoanalytic treatment. International Journal of Psychoanalysis, 39, 374-385.

Fonagy, P. Target, M., Gergely, G., \& Jurist, E. (2001). Affect regulation, mentalization, and the development of the self. New York: Other Press.

Flores, P.J. (2004). Addiction as an attachment disorder. Jason Aronson: Lanham.

Flores, P. J. (2001). Addiction as an attachment disorder: Implications for group therapy. International Journal of Group Psychotherapy, 51(1), 63-81.

Fraley, R. C., Waller, N. G., \& Brennan, K. A. (2000). An item-response theory analysis of self-report measures of adult attachment. Journal of Personality and Social Psychology, 78, 350-365.

Galanter, M., Talbott, D., Gallegos, K., \& Rubenstone, E. (1990). Combined Alcoholics Anonymous and professional care for addicted physicians, American Journal of Psychiatry, 47, 64-68.

George, C., Kaplan, N., Main, M. (1985). The Berkeley Adult Attachment Interview. Unpublished protocol. University of California, Berkeley.

Grant, B. F., Stinson, F. S., Dawson, D. A., Chou, P., Dufour, M. C., Compton, W., .. . 
Kaplan, K. (2004). Prevalence and co-occurrence of substance use disorders and independent mood and anxiety disorders: Results from the epidemiological survey on alcohol and related conditions. Archives of General Psychiatry, 61, 807-816.

Groh, D. R., Jason, L. A., \& Keys, C. B. (2008). Social network variables in alcoholics anonymous: A literature review. Clinical Psychology Review, 28(2008), 430-450. doi: 10.1016/j.cpr.2008.07.014

Gold, S. N. (2012). Abuse, trauma, and dissociation [PowerPoint slides].

Gusfield, J. R. (1975). The community: A critical response. New York: Harper Colophon. Hawkins, J. D., Catalano, R. F., \& Miller, J. Y. (1992). Risk and protective factors for alcohol and other drug problems in adolescence and early adulthood: Implications for substance abuse prevention. Psychological Bulletin, 112(1), 64-105.

Hazan, C., \& Shaver, P. (1987). Romantic love conceptualized as an attachment process. Journal of Personality and Social Psychology, 52(3), 511-524.

Hofstra, J. (2009). Attaching cultures: The role of attachment styles in explaining majority members' acculturation attitudes. University of Groningen. Groningen, The Netherlands.

Howes, C. (1999). Attachment relationships in the context of multiple caregivers. In J. Cassidy \& P.R. Shaver (Eds.). Handbook of attachment (pp. 671-687). New York: Milford Press.

Humphreys, K. (2004). Circles of recovery: Self-help organizations for addictions. Cambridge University Press: Cambridge, United Kingdom.

Humphreys, K., Wing, S., McCarty, D., Chappel, J., Gallant, L., Haberie, B., . . Weiss, 
R., (2004). Self-help organizations for alcohol and drug problems: Toward evidence-based practice and policy. Journal of Substance Abuse Treatment, 26(3), 151-158.

Humphreys, K., Mankowski, E., Moos, R. H., Finney, J. W. (1999). Do enhanced friendship networks and active coping mediate the effect of self-help groups on substance abuse? Annals of Behavioral Medicine 21(1), 54-60.

Humphreys, K., Finney, J. W., \& Moos, R. (1994). Applying a stress and coping perspective to research on mutual help organizations. Journal of Community Psychology, 22, 312-327.

John, O. P., Donahue, E. M., \& Kentle, R. L. (1991). The Big Five Inventory-versions 4a and 54. Berkeley, CA: University of California, Berkeley, Institute of Personality and Social Research.

Kaskutas, L. A., Bond, J., \& Humphreys, K. (2002). Social networks as mediators of the effect of Alcoholics Anonymous. Addiction, 97(7), 891-900.

Kassel, J. D., Wardle, M., \& Roberts, J. E. (2006). Adult attachment security and college student substance abuse. Addictive Behaviors, 32(6), 1164-1176. doi: 10.1016/j.addbeh.2006.08.005

Kelly, J., Magill, M., \& Stout, R. (2009). How do people recover from alcohol dependence? A systematic review of the research on mechanisms of behavior change in Alcoholics Anonymous. Addiction Research and Theory, 17(3), 236259.

Kennedy, J. H., \& Kennedy, C. E. (2004). Attachment theory: Implications for school psychology. Psychology in the Schools, 41(2), 247-259. doi: 10.1002/pits.10153 
Kessler, R. C., Mickelson, K. D., \& Zhao, S. (1997). Patterns and correlates of self-help group membership in the United States. Social Policy, 27(3), 27-46.

Krueger, R. F., Hicks, B. M., Patrick, C. J., Carlson, S. R., Iacono, W. G., \& McGue, M. (2002). Etiologic connections among substance dependence, antisocial behavior, and personality: Modeling the externalizing spectrum. Journal of Abnormal Psychology, 111(3), 411-424.

Lechliter, L. (2008). Insecure attachment styles, cluster B personality disorders, and gender as risk factors for substance abuse diagnoses. ProQuest Dissertations and Theses.

Lyons-Ruth, K., Alpern, L., \& Repacholi, B. (1993). Disorganized infant attachment classification and maternal psychosocial problems as predictors of hostileaggressive behavior in the preschool classroom. Child Development, 64, 572-585.

Magura, S., Laudet, A. B., Mahmood, D., Rosenblum, A., Vogel, H. S., \& Knight, E. L. (2003). Role of self-help processes in achieving abstinence among dually diagnosed persons. Addictive Behaviors, 28(3), 399-413.

Main, M., \& Solomon, J. (1986) Discovery of a new, insecure-disorganized/disoriented attachment pattern. In T. B. Brazelton \& M. Yogman (Eds), Affective development in infancy, pp. 95-124. Norwood, New Jersey: Ablex.

Maisto, S. A., Connors, G. J., \& Zywiak, W. H. (2000). Alcohol treatment, changes in coping skills, self-efficacy, and levels of alcohol use and related problems 1 year following treatment initiation. Psychology of Addictive Behaviors, 14(3), 257266.

Marvin, R., Cooper, G., Hoffman, K., \& Powell, B. (2002). The circle of security project: 
Attachment-based intervention with caregiver-preschool child dyads. Attachment and Human Development, 1(4), 107-124.

McMillan, D. W., \& Chavis, D. M. (1986). Sense of community: A definition and theory. Journal of Community Psychology, 14(1), 6-23.

Mikulincer, M., Shaver, P. R., Gillath, O.,\& Nitzberg, R. A. (2005). Attachment, caregiving, and altruism: Boosting attachment security increases compassion and helping. Journal of Personality and Social Psychology, 89(5), 817- 839. doi: $10.1037 / 0022-3514.89 .5 .817$

Moos, R. H. (2008). How and why twelve-step self-help groups are effective. In M. Galanter \& L. A. Kaskutas (Eds.), Recent developments in alcoholism (pp. 393412). New York, NY: Springer.

Morgenstern, J. \& Leeds, J. (1993). Contemporary psychoanalytic theories of substance abuse: A disorder in search of paradigm. Psychotherapy, 30(2), 194-206. doi: $10.1037 / 0033-3204.30 .2 .194$

Morgenstern J., \& McKay, J. (2007). Rethinking the paradigms that inform behavioral treatment research for substance use disorders. Addiction, 102(9), 1377-1389.

Narcotics Anonymous World Services. (2012). World Pool Information Form. Retrieved February 20, 2013, from http://www.na.org/admin/include/spaw2/uploads/pdf/HRP/2012Aug_WPIF.pdf Narcotics Anonymous World Services (1986). Twelve Steps. [Little White Booklet]. Van Nuys, CA: Narcotics Anonymous World Services, Inc.

Ormont, L. (2001). The importance of the contract in resolving resistances to progress: A 
critique of a therapy group. In L B. Furgeri (Ed.), The technique of group treatment: The collected papers of Louis R. Ormont, PhD. Madison, CT: Psychosocial Press.

Pagano, M. E., Friend, K. B., Tonigan, J. S., \& Stout, R. L. (2004). Helping other alcoholics in Alcoholics Anonymous and drinking outcomes: Findings from Project Match. Journal of Studies on Alcohol, 65(6), 766-773.

Petraitis, J., Flay, B. R., \& Miller, T. Q. (1995). Reviewing theories of adolescent substance use: Organizing pieces in the puzzle. Psychological Bulletin, 117(1), 67-86.

Proescholdbell, R. J., Roosa, M. W., \& Nemeroff, C. J. (2006). Component measures of psychological sense of community among gay men. Journal of Community Psychology, 34(1), 9-24.

Project MATCH Research Group (1997). Matching alcoholism treatments to client heterogeneity: Project MATCH posttreatment drinking outcomes. Journal of Studies on Alcohol, 58(1997), 7-29.

Rammstedt, B., \& John, O. P. (2007). Measuring personality in one minute or less: A 10item short version of the Big Five Inventory in English and German. Journal of Research in Personality, 41, 203-212.

Roberts, L., Salem, D., Rappaport, J., Toro, P., Luke, D., and Seidman, E. (1999). Giving and receiving help: Interpersonal transactions in mutual-help meetings and psychosocial adjustment of members. American Journal of Community Psychology, 27, 841-868.

Rohde, P., Stice, E., Gau, J. M., \& Marti, C. N. (2012). Reduced substance use as a 
secondary benefit of an indicated cognitive-behavioral adolescent depression prevention program. Psychology of Addictive Behavior. Advance online publication. doi: 10.1037/a0028269

Ryff, C. D., \& Keyes, C. L. M. (1995). The structure of psychological well-being revisited. Journal of Personality and Social Psychology, 69(4), 719-727. doi: $10.1037 / 0022-3514.69 .4 .719$

Sarason, S. B. (1974). The psychological sense of community: Prospects for a community psychology. Cambridge, MA: Brookline Books, Inc.

Schaffer, H. R., \& Emerson, P. E. (1964). The development of social attachments in infancy. Monographs of the Society for Research in Child Development, 29(3), serial number 94 .

Schiff, M., \& Bargal, D. (2000). Helping characteristics of self-help and support groups: Their contribution to participants' subjective well-being. Small Group Research, 31(3), 275-304.

Schwartz, C. E., Meisenhelder, J. B., Ma, Y., \& Reed, G. (2003). Altruistic social interest behaviors are associated with better mental health. Psychosomatic Medicine, 65, $778-785$.

Schwartz, C. E., \& Sendor, M. (1999). Helping others helps oneself: Response shift in peer support. Social Science Medicine, 48(11), 1563-75.

Schechtman, Z., \& Rybko, J. (2004). Attachment style and observed initial selfdisclosure as explanatory variables of group functioning. Group Dynamics: Theory, Research, and Practice, 8(3), 207-220.

Sher, K. J. (1991). Children of alcoholics: A critical appraisal of theory and research. 
Chicago: University of Chicago Press.

Sher, K. J., Grekin, E., \& Williams, N. (2005). The development of alcohol problems. Annual Review of Clinical Psychology, 1,_493-523.

Slade, A., Grienenberger, J., Bernbach, E., Levy, D., \& Locker, A. (2005). Maternal reflective functioning, attachment, and the transmission gap: a preliminary study. Attachment and Human Development, 7(3), 283-298.

Slade, A. (2004). The move from categories to process: Attachment phenomena and clinical evaluation. Infant Mental Health Journal, 25(4), 269-283.

Slutske, W. S., Heath, A. C., Dinwiddie, S. H., Madden, P. A. F., Bucholz, K. K., Dunne, M. P., Statham, D. J., \& Martin, N.G. (1998). Common genetic risk factors for conduct disorder and alcohol dependence. Journal of Abnormal Psychology, 107(3), 363-374.

Smith, B. W., \& Tonigan, J. S. (2009). Alcoholics anonymous benefit and social attachment. Alcoholism Treatment Quarterly, 27, 164-173.

Sroufe, L. A., Carlson, E. A., Levy, A.K., Egeland, B. Implications of attachment theory for developmental psychology. Development \& Psychopathology, 11, 1-13.

Stein, H., Koontz, D., Fonagy, P., Allen, J. G., Fultz, J., Brethour, J. R., Allen, D., \& Evants, R. B. (2002). Adult attachment: What are the underlying dimensions? Psychology and Psychotherapy: Theory, Research, and Practice, 75, 77-91.

Stice, E., \& Barrera, M. (1995). A longitudinal examination of the reciprocal relations between perceived parenting and adolescents substance use and externalizing behaviors. Developmental Psychology, 31(2), 322-334. doi: 10.1037/00121649.31 .2 .322 
Substance Abuse \& Mental Health Services Administration. (2008). National registry of substance abuse programs and practices. Washington, D.C: U.S. Department of Health and Human Services.

Watson, M. (2002). Lectures 13, 14, 15 on Attachment Theory. Theories of human development, Part I. Chantilly, VA: The Teaching Company.

Tucker, J., Vuchinich, R. E., \& Sobell, M. B. (1981). Alcohol consumption as a selfhandicapping strategy. Journal of Abnormal Psychology, 90(3), 220-230. doi: 10.1037/0021-843X.90.3.220

Walant, K. B. (1995). Creating the capacity for attachment: Treating addictions and the alienated self. Northvale, NJ: Jason Aronson.

Waters, E., Merrick, S., Treboux, D., Crowell, J., \& Albersheim, L. (2000). Child Development, 71(3), 684-689.

Zemore, S. E., \& Pagano, M. E. (2008). Kickbacks from helping others: Health and recovery. In M. Galanter \& L. A. Kaskutas (Eds.), Recent developments in alcoholism (pp. 141-166). New York, NY: Springer. 
Appendix A

Social Support (SOSU)

Please answer the following questions about people IN RECOVERY.

- How many people IN RECOVERY currently provide you with support? (e.g., listen to you when you need to talk, do you a favor-like give you a ride).

- How many of these people IN RECOVERY who provide you with support do you talk to at least once every two weeks?

Please answer the following questions about people NOT IN RECOVERY.

- How many people NOT IN RECOVERY currently provide you with support? (e.g., listen to you when you need to talk, do you a favor-like give you a ride).

- How many of these people NOT IN RECOVERY who provide you with support do you talk to at least once every two weeks?

- How many would you consider to be problem drinkers or drug users?

- How many ask you to drink alcohol or use other drugs with them?

During the PAST 3 MONTHS, how often have you needed EMOTIONAL support? By EMOTIONAL support, we mean things like someone listening to your problems or encouraging you to face fears (just to name two things).

\begin{tabular}{|c|c|c|c|c|c|}
\hline $\begin{array}{c}\text { No need at } \\
\text { all }\end{array}$ & $\begin{array}{c}\text { A little } \\
\text { need }\end{array}$ & $\begin{array}{c}\text { Moderate } \\
\text { need }\end{array}$ & $\begin{array}{c}\text { A lot of } \\
\text { need }\end{array}$ & Great need & $\begin{array}{c}\text { I choose not to } \\
\text { answer }\end{array}$ \\
\hline
\end{tabular}

During the PAST 3 MONTHS:

- How many people IN RECOVERY have provided EMOTIONAL support?

During the PAST 3 MONTHS, how helpful was the EMOTIONAL support you received from people IN RECOVERY?

\begin{tabular}{|l|l|l|l|l|l|}
\hline $\begin{array}{l}\text { I have not } \\
\text { received } \\
\text { emotional } \\
\text { support from } \\
\text { people in } \\
\text { recovery }\end{array}$ & $\begin{array}{l}\text { Not at all } \\
\text { helpful }\end{array}$ & $\begin{array}{l}\text { Slightly } \\
\text { helpful }\end{array}$ & $\begin{array}{l}\text { Moderately } \\
\text { helpful }\end{array}$ & Very helpful & $\begin{array}{l}\text { I choose } \\
\text { not to } \\
\text { answer }\end{array}$ \\
\hline
\end{tabular}

During the PAST 3 MONTHS:

- How many people NOT IN RECOVERY have provided EMOTIONAL support?

During the PAST 3 MONTHS, how helpful was the EMOTIONAL support you received from people NOT IN RECOVERY?

\begin{tabular}{|l|l|l|l|l|l|}
\hline $\begin{array}{l}\text { I have not } \\
\text { received } \\
\text { emotional } \\
\text { support from } \\
\text { people in } \\
\text { recovery }\end{array}$ & $\begin{array}{l}\text { Not at all } \\
\text { helpful }\end{array}$ & $\begin{array}{l}\text { Slightly } \\
\text { helpful }\end{array}$ & $\begin{array}{l}\text { Moderately } \\
\text { helpful }\end{array}$ & Very helpful & $\begin{array}{l}\text { I choose } \\
\text { not to } \\
\text { answer }\end{array}$ \\
\hline
\end{tabular}


During the PAST 3 MONTHS, how often have you needed PRACTICAL support? By PRACTICAL support, we mean things like someone giving you a ride or watching your children (just to name two things).

\begin{tabular}{|l|l|l|l|l|l|}
\hline $\begin{array}{l}\text { No need at } \\
\text { all }\end{array}$ & $\begin{array}{l}\text { A little } \\
\text { need }\end{array}$ & $\begin{array}{l}\text { Moderate } \\
\text { need }\end{array}$ & $\begin{array}{l}\text { A lot of } \\
\text { need }\end{array}$ & Great need & $\begin{array}{l}\text { I choose not to } \\
\text { answer }\end{array}$ \\
\hline
\end{tabular}

During the PAST 3 MONTHS:

- How many people IN RECOVERY have provided PRACTICAL support?

During the PAST 3 MONTHS, how helpful was the PRACTICAL support you received from people IN RECOVERY?

\begin{tabular}{|l|l|l|l|l|l|}
\hline $\begin{array}{l}\text { I have not } \\
\text { received } \\
\text { emotional } \\
\text { support from } \\
\text { people in } \\
\text { recovery }\end{array}$ & $\begin{array}{l}\text { Not at all } \\
\text { helpful }\end{array}$ & $\begin{array}{l}\text { Slightly } \\
\text { helpful }\end{array}$ & $\begin{array}{l}\text { Moderately } \\
\text { helpful }\end{array}$ & Very helpful & $\begin{array}{l}\text { I choose } \\
\text { not to } \\
\text { answer }\end{array}$ \\
\hline
\end{tabular}

During the PAST 3 MONTHS:

- How many people NOT IN RECOVERY have provided PRACTICAL support?

During the PAST 3 MONTHS, how helpful was the PRACTICAL support you received from people NOT IN RECOVERY?

\begin{tabular}{|l|l|l|l|l|l|}
\hline $\begin{array}{l}\text { I have not } \\
\text { received } \\
\text { emotional } \\
\text { support from } \\
\text { people in } \\
\text { recovery }\end{array}$ & $\begin{array}{l}\text { Not at all } \\
\text { helpful }\end{array}$ & $\begin{array}{l}\text { Slightly } \\
\text { helpful }\end{array}$ & $\begin{array}{l}\text { Moderately } \\
\text { helpful }\end{array}$ & Very helpful & $\begin{array}{l}\text { I choose } \\
\text { not to } \\
\text { answer }\end{array}$ \\
\hline
\end{tabular}

